This is a post-peer-review, pre-copyedit version of an article published in Journal of Business Ethics. The final authenticated version is available online at: http://dx.doi.org/10.1007/s10551-018-3977-0

\title{
The Impact of Culture on Corruption,
}

\section{Gross Domestic Product, and Human Development}

\author{
Running head: Culture and Corruption
}

Wolfgang Scholl, Carsten C. Schermuly

Wolfgang Scholl ( $₫)$, Institut für Psychology, Humboldt-Universität zu Berlin, Germany, Unter den Linden 6, 10099 Berlin

e-mail: schollwo@hu-berlin.de, phone: +49-30-41705008

Carsten C. Schermuly, SRH Hochschule, Berlin, Germany, Ernst-Reuter-Platz 10, 10587 Berlin

e-mail: carsten.schermuly@srh.de

\section{Acknowledgements}

Many thanks to Peter Graeff, Michael Johnston, Nils Köbis, Johann Graf Lambsdorff, and Stefan Melnik for helpful commentaries and to all authors and institutions who made their multi-nations data available. We especially thank the section editor, Dr. Suhaib Riaz, and the anonymous reviewers for their valuable suggestions for improving the paper.

\section{Funding:}

This research did not receive any specific grant from funding agencies in the public, commercial, or not-for-profit sectors.

There are no conflicts of interests. 


\title{
The Impact of Culture on Corruption,
}

\section{Gross Domestic Product, and Human Development}

\author{
By Wolfgang Scholl \& Carsten C. Schermuly \\ Author's Accepted Manuscript, Journal of Business Ethics, doi: 10.1007/s10551-018-3977-0
}

\begin{abstract}
The evidence of culture's impact on corruption and its consequences is still inconclusive despite several investigations: (1) Sometimes, theory is lacking and causes and consequences seem exchangeable. Based on psychological research on the distribution and use of power, we predicted that a steeper distribution of power induces more corruption and elaborated its negative consequences in a complex causal model. (2) For measuring power distribution, pervading national culture, we augmented Hofstede's 'Power Distance' with three additional indicators into a reversed, more reliable and valid culture composite called "Power Balanced Freedom" (PBF). (3) Instead of the usual regression and instrument approaches, which cannot estimate multiple causal chains including causal feedback, a nonrecursive path analysis was employed with data from 85 nations. PBF predicted less national Corruption (62\%), with positive effects on Gross Domestic Product (GDP, 72\%) and Inequality Adjusted Human Development (IHDI, 66\%, including Life Expectancy, Income, and Education). The often expected reverse effect of GDP on Corruption was not significant. Contrary to influential authors from economics, culture variables are the most important predictors of corruption and its consequences. Nonetheless, our extended model supports the main thrust of their ideas and adds more precision. Our conceptual distinction of the uses of power and our empirical measure PBF reflect Kant's ethical imperative: freedom and autonomy for everyone. Widely shared life chances as measured by IHDI reflect utilitarian, consequentialist ideas. These different ethical approaches are connected in the confirmed causal model, in line with Rawls' first and second principle of justice.
\end{abstract}

Keywords: Corruption; Cross Cultural Differences; Economics; Freedom; GLOBE; Hofstede; Human Development; Power Distribution; Psychology.

\section{Introduction}

Corruption plagues the world, especially in the less developed countries. The United Nations proposed 17 sustainable development goals to improve human well-being. Goal 16 reads, "promote just, peaceful, and inclusive societies." One of its targets says "Substantially reduce corruption and bribery in all their forms" (United Nations, 2016). In the introduction of their representative book on corruption and government, Rose-Ackerman and Palifka $(2016,28)$ summarized the research assumptions and findings about corruption into 9 causes and 13 consequences. Culture is declared as one of the minor causes of corruption, analyzed primarily with regard to gender and religion. The authors concluded that neither gender nor religion "provide much insight into the root causes of corruption." (Rose-Ackerman and Palifka, 2016, p. 248). In contrast, we will show that culture is a very potent factor that 
explains cross-country variations in corruption if appropriate culture measurement is used instead of percentages of women or of religion members. "Culture provides guidelines or roadmaps on what to do, how to think, and what to feel. Those guidelines are passed along from one generation to the next" (Matsumoto and Hwang, 2013). Cultural guidelines "result from common experiences of members of collectives" (House et al., 2004, p. 15), which influence "their practices, institutions, symbols, artifacts, beliefs, and values" (Heine, 2012, p. 12).

Using available data from culture surveys, we generated an appropriate measurement approach, based on a theory of the main cause of corruption. A recent meta-analysis (Judge, et al. 2011) found that most empirical culture-and-corruption studies had no appropriate theoretical model. Our theoretical starting point is Transparency International's definition of corruption: "The abuse of entrusted power for private gain" (2016), which points to the decisive role of a proper distinction between uses and abuses of power. "Abuse" can be interpreted as a theoretical concept as well as a normative term, asking for an ethical discussion (more see next section). To make the theoretical concept and its empirical operationalization more explicit: Using entrusted power for corruption "involves a holder of public office violating the impartiality principle in order to achieve private gain" (Rothstein and Teorell, 2008, p. 171). Thus, citizens are exploited and experience private losses whereas public officials and some corrupting citizens receive private benefits.

The insight of Baron Acton, based on his historical studies, provides a strong hint for the primary cause of corruption: "Power tends to corrupt, and absolute power corrupts absolutely" (Dalberg-Acton, 1907, p. 504). So, we will first explore the concept of power and the nomological network which connects power distribution with corruption and its consequences. In the methods section we present an appropriate empirical approach including a more reliable and valid culture measure of national power distribution. The third section presents the empirical results, followed by an extensive discussion in the fourth section.

\subsection{Differentiating the Uses of Power and their Relation to Corruption}

For relating power conceptually and theoretically to corruption, we first have to clarify the theoretical concept of power and its uses. Power is a basic dimension of all types of social relations (Scholl, 2013), together with the most important social dimension, affiliation (see Figure 1$)^{2}$. Power is usually defined as a relational potential, following Weber: "Power means any chance to realize one's own will within a social relationship, even against resistance, no matter how this chance is founded" (Weber 1921/1972). It's important to note that power as a potential says nothing about whether and how it is used, without or against resistance. Power, personal as well as institutional, can be used in a friendly, promotive way, respecting the interests and the autonomy of others. With this type of power use, termed promotive control, powerful actors aim for acceptance by the other, e.g. giving information and good advice, remaining fair in competition, or seeking win-win-solutions in conflicts and negotiations. Power can also be used in an ignorant or hostile way, disregarding and violating the interests and the autonomy of others. With this type of power use, termed restrictive control, powerful actors aim for compliance by the other or to break presumed resistance, e.g. slapping children, giving orders without asking for consent, mobbing colleagues, or deceiving superiors. Targets 
always evaluate other's use of power along the affiliation dimension as more or less friendly, as accepting their autonomy, or hostile, as violating their autonomy (see Figure 1), and this is decisive for their cooperation or resistance. These two ways of using power have quite different consequences for all involved, the targets, the agents, and the respective social unit (Buschmeier, 1995; Chen et al., 2001; Cialdini, 1993; Elias, 2009; Etzioni, 1968; Scholl, 1999; Scholl and Riedel, 2010; Singh-Sengupta, 1997) ${ }^{3}$. Probably all humans experience and distinguish promotive as well as restrictive uses of power by their parents as children, later on among peers, within hierarchies, or between nations. So, individuals, organizations, and nations always rate, whether relevant others are stronger, equal, or weaker in power, and whether their affiliation tendency is friendly, neutral, or hostile.

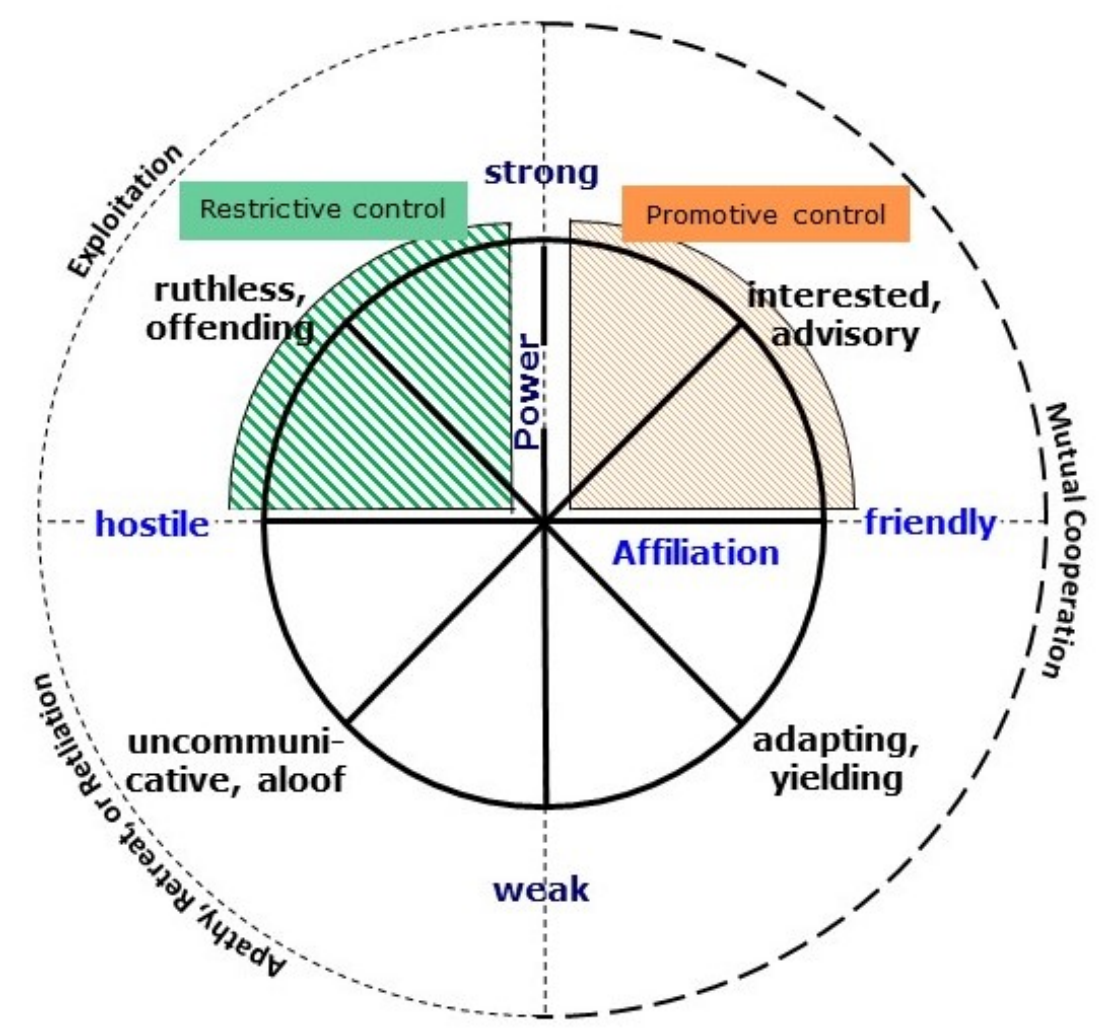

Figure 1. Affiliation and power as basic social dimensions and their combinations.

This differentiation of promotive and restrictive control as theoretical concepts also has ethical relevance. Respecting the autonomy of the other with promotive control is in line with Kant's categorical imperative: "Act in such a way that you treat humanity, whether in your own person or in the person of any other, never merely as a means to an end, but always at the same time as an end" (Kant, 1993, p. $36^{4}$ ). Restrictive control violates the autonomy of the other and is therefore incompatible with the categorical imperative. "Restrictive control" gives a more precise meaning to "Abuse of power" in Transparency International's corruption definition: as a theoretical concept, the main application here, as well as an ethical judgement, taken up in section 4.4 .

Corruption is an important example of using one's power as restrictive control, ignoring and violating the interests of the public at large and the equal rights and claims of the other citizens. Material corruption is a facet of moral corruption. In differentiating the level of 
power as a potential from the use of such a potential in a promotive or restrictive way, we can reformulate the above-cited famous saying of Baron Acton: "Superior power tends to induce people to use their power for their own advantage restrictively, i.e. against the interests of the other, and thus it corrupts those moral considerations which respect the autonomy of others. Absolute, uncontrollable power is most likely to be used restrictively, it corrupts absolutely". In short: Larger power distributions induce more corruption.

\subsection{Insights from psychological research on power}

Psychological research confirmed Baron's assumption about an uneven power distribution. Kipnis (1976) demonstrated experimentally that not only the targets are affected by restrictive control, but also the agents. The student participants in his experiment were required to act as superiors in an industrial simulation experiment, and their subordinates were students in another building. Superiors received identical feedback about their subordinate's performance in both conditions exercised. In one condition, they were equipped with coercive (= restrictive) means of power, such as salary reductions or withholding salary increases, threatening or imposing a transfer to another job, and threatening or imposing job termination. They used their power to sanction their subordinates, and they attributed the work results primarily to their own leadership efforts. In the other condition, superiors were only equipped with the more promotive means of legitimacy and argumentation and they attributed the work results to their common efforts ${ }^{5}$. Only the users of restrictive control justified their behavior by devaluing their targets, and they distanced themselves from their co-subjects drawn as subordinates. Kipnis (1976) calls these attributional biases and justifications the "metamorphic effect of power" and cites Baron Acton: "Power tends to corrupt, and absolute power corrupts absolutely".

Moral transgression and justification as a consequence of using elevated power as restrictive control was also found in other experimental and field research (Buschmeier, 1995; Georgesen and Harris, 1998; Lee-Chai and Bargh, 2001; Mitchell et al., 1998). And moral corruption facilitates material corruption. In a study with 150 enterprises, the researchers found that if executives were less controlled, i.e. the more superior power they had, illegal behavior and material corruption became more frequent (Mitchell et al. 1998). In following Kipnis' (1976) seminal research, Keltner et al. (2003) reviewed further details from experimental research on high versus low power manipulations which are relevant in the corruption context: High versus low power individuals are more likely to see others as means to own ends, exhibit a higher self-focus, construe others in a more stereotypic way, are more inaccurate in their inferences, practice more out-group discrimination and show more disinhibited, counternormative behavior. These tendencies are moderated by individual characteristics as well as by the instability of the power relationship, by the extent of accountability, and by cultural influences.

We expect that these findings have consequences at the cultural/national level: Countries with larger power distributions and steeper hierarchies, like dictatorial and autocratic regimes, provide more opportunities to enrich oneself at the expense of others because there is less fear to be detected, publicly accused, discredited, or sentenced. In line 
with the above-mentioned moderators, powerholders in those countries are less controlled and power relations are stabilized by the powerholders themselves, much more than in countries with more balanced power distributions, e. g. well-established, full democracies with their checks and balances. This uncontrolled-power-corrupts effect primarily fuels grand corruption and political corruption. Petty corruption at lower levels may be facilitated by the consequences of political corruption, the establishment of less controllable public institutions and restrictive control action patterns ${ }^{6}$. This delivers our first hypothesis:

H 1: Larger, culturally ingrained power distributions, accompanied by special culturalideological justifications, induce more corruption in the respective societies.

\subsection{Consequences of corruption}

Another important aspect of an unequal power distribution and corruption pertains to the consequences for the work to be done. Using power as restrictive control impairs the free flow of information and the open discussion of arguments. Dominant power holders are not really interested in divergent information and opinions, which they often suppress (Scholl, 1999). Consequently, targets either become angry, try to resist, oppose, and retaliate to restore their autonomy, i.e. they answer with restrictive control, if they are powerful enough. Otherwise, they feel helpless, fear further damages, retreat, and avoid collaboration (Keltner et al., 2003; Wortman and Brehm, 1975; see the lower left sector in Figure 1). Thus, restrictive control is detrimental for gaining appropriate knowledge in all kinds of common endeavors, which lowers the effectiveness of the relevant social unit. Individual competences can best be developed and become productive when promotive control prevails, because differing opinions are uttered and respected, they lead to intensive discussions, and conflicts of opinions and interests are constructively managed. These hypotheses have been confirmed experimentally as well as in field studies of innovation processes (Buschmeier, 1995; Scholl, 1999, 2014; Scholl and Riedel, 2010).

We expect that these empirically confirmed hypotheses are also valid at the societal level. Cultures and nations with larger power differences may not only exhibit the well-known diversion, tax evasion, and lower domestic and foreign investment effects of corruption on countries' economic performance, measured by gross domestic product (GDP) (Lambsdorff, 2006). Corruption as a manifestation of restrictive control will probably lead to less interest in collaborative learning and to more resistance or helplessness, resulting in less knowledge production and lower performance (GDP). Both theoretical lines together may better explain the often found strong correlation between national corruption and lower GDP (RoseAckerman and Palifka, 2016, p. 30) than the former alone. Throughout history, dominating elites and powerholders do not only organize the political and economic sphere into a corrupt system for their own advantage, they are also not inclined to promote open and critical discussions which might endanger this regime; ironically, they thereby gradually devastate their country (Acemoglu and Robinson, 2012). These arguments and results from diverse strands of research on the interpersonal, organizational, and national level converge to the second hypothesis: 
H 2: The amount of corruption as a manifestation of restrictive control reduces the economic performance of a country as measured by its gross domestic product (GDP)

The negative impact of corruption on GDP seems to be common economic wisdom (RoseAckerman and Palifka, 2016, p. 28). However, the causal relation between national corruption and GDP is still disputed, because the inducements for corruption might be stronger in poorer, less developed countries with fewer developed institutions to monitor corruption, or their officials use bribery to improve their sparse living conditions (Treisman, 2007). Culture-andcorruption studies often use GDP or GNP (Gross National Product) not as a dependent measure but as a predictor of corruption without substantiating their claim (Akbar and Vujić, 2014; Cheung and Chan, 2008; Husted, 1999). Perhaps a mutual causation exists, but the arguments above and the economic literature (see the discussion in Rose-Ackerman and Palifka, 2016) favor our third hypothesis:

H 3: The corruption-reduces-GDP effect is much stronger than the reverse path, GDPreduces-corruption, because of the manifold different negative effects of corruption.

Despite the wide use of GDP as a standard measure for the wealth of nations, it is criticized as a less suited indicator for the well-being of a population. For example, more crime might increase the need for more police members, attorneys, prosecutors, judges, and prisons, increasing GDP, but crime does not increase the well-being of the majority (Stiglitz et al., 2010). Therefore, the United Nations developed the Inequality-adjusted Human Development Index (IHDI), which combines inequality-adjusted data for life expectancy, education (years of schooling), and income. This index represents how good and widely shared life chances are in each nation (United Nations Development Programme, 2014, see technical notes 1 and 2 at http://hdr.undp.org/en/content/human-development-report-2014 for details on how HDI and its modification into IHDI is calculated). Of course, IHDI depends on resources available and thus on GDP. And the adjustment for inequality corrects the possibility that a small percentage of very rich people raises the national average substantially and somewhat conceals the misery of the poor. For some countries, the differences between HDI and IHDI are remarkable. For example, whereas the USA ranked no. 5 in the world on the HDI in 2013, only behind the three richest European countries and Australia, it dropped 23 positions on the IHDI and ranked behind 23 European countries, including the former socialist Middle-European countries Slovenia, Slovakia, and Czech Republic, which gained 9 ranks on the IHDI compared to HDI. Inequality adjustment with IHDI is preferable to HDI, with its pure averages, from a theoretical and an ethical point of view. Theoretically, the consequences of corruption for life expectancy, income, and education of a population become better recognizable if the exploited strata get more weight. Therefore, we predict that corruption also has a direct negative effect on IHDI. And this recognition is also preferable 
from an ethical point of view (cf. Rawls' principles of justice, 2001), because their human dignity and their choice opportunities are in practice more or less denied.

H 4: Inequality-adjusted Human Development (IHDI) is hypothesized to depend positively on GDP, because high standards need many resources.

H 5: Inequality-adjusted Human Development (IHDI) is hypothesized to depend negatively on corruption, because corruption implies a redistribution of benefits to higher, more powerful strata.

These five hypotheses form the core of a more encompassing theoretical model. It is closely connected with the statistical approach of path analysis which is presented in the next section.

\section{Method}

The empirical analysis of the developed causal hypotheses, including the causal feedback hypothesis 3 , uses a cross-sectional design with available data from 85 nations. The only statistical approach for disentangling causal feedback effects are structural equation systems, in our case especially path analysis. This method is explained first because it may not be familiar to all readers. In 2.2, possible measures of national power distribution are discussed, and in 2.3 an improved measure is developed. Finally, in 2.4, all other variables needed for the causal model are described.

\subsection{Path Analysis}

Statistical analyses of complex causal models in non-experimental settings are best performed with longitudinal designs and structural equation models for latent variables measured via multiple indicators (Hoyle, 2012). Regrettably, neither a longitudinal design nor a latent variable approach is feasible in the chosen context. On the one hand, the used multinational culture surveys were one-shot cross-sectional investigations. On the other, most model variables are manifest (see the full model below in fig. 2) and are not decomposable into an array of indicators. Moreover, the number of proposed effects for estimating the model must be kept low compared to the available observation units to produce stable estimations; recommended is a sample size 5 to 10 times the number of parameters to be estimated (Bagozzi and Yi, 2012); in our analyses, the sample size fulfills the 10 times criterion. Thus, a cross-sectional path analysis, a special case of structural equation modeling, is the relevant alternative. "Path analysis models are used when MVs [measured variables] are of primary interest or when multiple indicators of LVs [latent variables] are not available." (MacCallum and Austin, $2000^{7}$ ).

Path analysis with manifest variables was developed by geneticist Sewall Wright in the first half of the $20^{\text {th }}$ century and then was mainly adopted for sociological questions (Duncan, 1966; Blalock, 1971). Path analysis has two main advantages over the usual regression approaches in culture and corruption studies. Most important in our context: It is impossible to estimate causal feedback, as implied in H3, with regressions. The same caveat 
also applies to the use of instrumental variables with regressions. For testing causal feedback hypotheses like $\mathrm{H} 3$, the common variance must be partitioned into two causal directions, estimating both effects simultaneously. Regression approaches, on the other hand, can only test one causal direction at a time, first for one direction, and then a second time for the other direction. Thus, the common variance between the two variables will not be partitioned, but most likely fully exploited in each of the two regressions. In one often cited article, Husted (1999) conceded with reference to Mauro (1995) "that reverse causality may exist" between Gross National Product (a proxy of GDP) and the level of corruption (p. 342). Yet, he only regressed corruption onto GNP and Hofstede's cultural dimensions; that is, from a theoretical point of view, a misspecification if reverse causality is assumed ${ }^{8}$. Aidt et al. (2008, p. 196) also assume a direct causal feedback effect, at least for the more developed countries: "High growth reduces corruption which, in turn, increases growth". But instead of a simultaneous estimation of both effects, they administer two separate regression equations with instrumental variables for corruption on the one hand and for GDP growth on the other. Both regression sets deliver significant effects but the main problem remains unresolved: Using regressions deliver estimates for one causal direction but they do not include the causal feedback effect of the other direction which might further reduce the available variance to be explained by the first effect. With path analysis, on the other hand, reciprocal influence between two variables can be simultaneously tested for correspondence with empirical data within a larger fully specified theoretical structure (cf. early examples in Duncan et al., 1971).

The second advantage of path analysis over regressions is this necessity to fully specify a more complex theoretical structure. This includes not only which causal paths are assumed between the model variables, but also mediation effects via indirect paths where direct paths are set to zero. Further assumptions have to be made whether all important exogenous variables are included in the model, i.e. whether the possible paths between errors of the endogenous variables with any other endogenous or exogenous variable really can be assumed as uncorrelated and set to zero (Hoyle, 2012). Otherwise, correlations between the concerned errors have to and can be explicitly brought into the model specification. All these assumptions are tested in path analysis by a simultaneous computation of the structural equations for the endogenous variables. With path analysis, whole nomological networks are analyzed and tested for "goodness of fit" of the complete model whereas regressions analyze possible predictors of one dependent variable for "significant difference from zero" (Hoyle, 2012). 


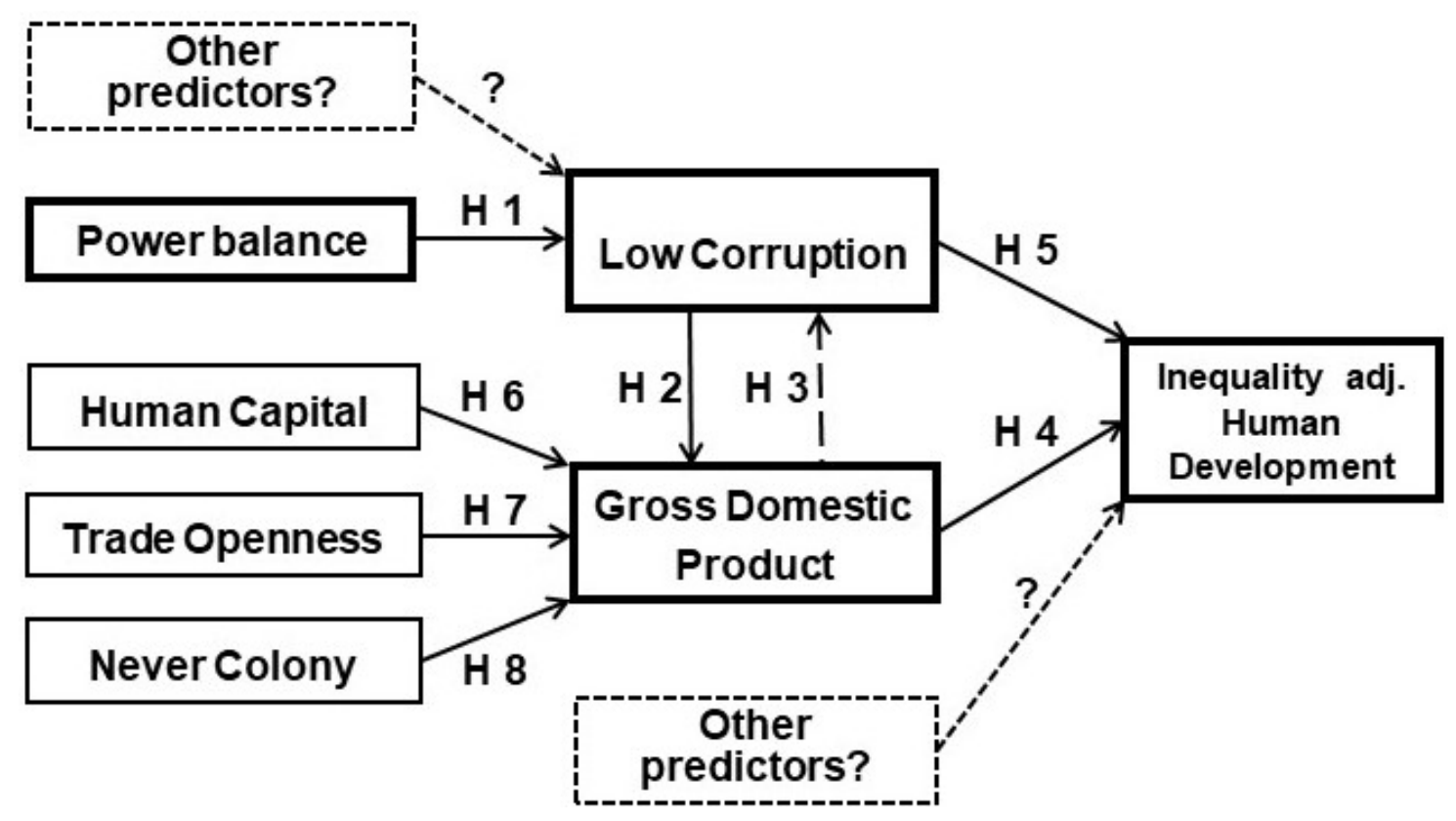

Figure 2. Theoretical model to be estimated.

Note. Unknown causal assumptions are indicated with question marks and dotted lines.

Therefore, the basic theoretical model implied in the hypotheses $1-5$ was augmented in two ways: First, our model had to include additional predictors of GDP that are largely uncorrelated with corruption and its predictor(s) in order to make the estimation of GDP identifiable and predictable independently from corruption. These additional predictors should explain as much variance as possible. In fact, they play a similar role in the path model as instrumental variables in the regression approach. The following predictors of GDP, which are often discussed and empirically confirmed in the economic literature, were adopted as hypotheses and added to our path analytic model: Education as a proxy for Human Capital has been brought to the forefront as a critical predictor for GDP (Baldwin et al., 2011; Hanushek and Woessmann, 2012). Trade Openness is another positive predictor of GDP, substantiated in the corruption literature by Aidt (2011) and Johnston (2014). And a third, quite different predictor of GDP is Former Colonial Status of a country, which impairs social and economic development (Treisman, 2007). Additional predictors from the data set of Treisman (2007) are probed in the current study to explain as much variance as possible of corruption beneath (low) power distribution and IHDI (see the dotted arrows in figure 2).

H 6-8: GDP depends positively on Human Capital (H 6), Trade Openness (H 7) and if a country was Never a Colony (H 8), as shown in former research.

The second theoretical extension is the specification of all possible relations between the model variables; which are not assumed to be direct causal effects and are therefore fixed to zero. As shown in the full model to be tested in figure 2, we omitted 8 connections between exogenous and endogenous variables so that they are fixed to zero for the calculations. In other words, path analysis includes mediation analyses (Hoyle, 2012; see Baldwin et al., 2011, for an economic example): it tests all theoretical specifications that directly or indirectly or not at all connect antecedent to endogenous variables, including direct and indirect effects 
at the same time (as, for instance, corruption to IHDI in figure 2). These 8 zero parameters (the omitted connections in figure 2) need not be estimated and can serve as additional test values for the empirical tenability of the theoretical model. In a sense, these additional 8 zero hypotheses are the strongest ones because an exact value, zero, is predicted, not a range of possible values as in the hypotheses $1-8$.

The logic of this nomological network approach is based on the fundamental path theorem: Each endogenous variable is considered as completely determined by other variables in the network, including the residuals. The empirical estimation is based on the consequence that each correlation with an endogenous variable can be completely decomposed into all path coefficients and their indirect and correlated combinations leading from the antecedent variable to the endogenous variable (Duncan,1966). For instance, if we theorize IHDI (I) as directly dependent on Corruption (C) (H5 in figure 2) and also assume an indirect path via GDP (G) (H2 und H4), then the correlation can be decomposed into the path coefficients $\mathrm{p}_{\mathrm{ij}}$ (equivalent to standardized regression coefficients) in the following way: $r_{I C}=p_{I C}+p_{G C} p_{I G}$, i.e. indirect connections are calculated by multiplication of the connecting direct paths. If we instead assume that GDP causes corruption, then the path coefficient would just equal the correlation: $r_{I C}=p_{I C}$. If we assume reciprocal influence between corruption and GDP, then the correlation would be decomposed into $r_{I C}=p_{I C}+p_{G C} p_{I G}+p_{G C} p_{C G} p_{I C}$. The path analytic algorithm tests how well all these path implications between all variables of the model are compatible with the empirical correlations. Path $\mathrm{H} 2$ has to be nearly identical within four different causal chains of the model, and the paths H3, H4, and H5 within six different chains. 20 further possible chains are expected to be zero because they would contain a missing direct path, which is set to zero, so that all multiplications with existing path coefficients also become zero 9 . Thus, path analysis does not only look for good predictors of a presumed variable but evaluates complex causal orderings in every detail. More specifically, the simultaneous estimation of the fully specified model includes an estimation of both paths between corruption and GDP and thus can test which amount of the two effects is compatible with the implied decompositions of the different relevant causal chains.

The theoretical discussion suggested those paths which are firmly anchored in former research, but some open questions remain as shown by the dotted arrows in figure 2. There might be some additional effects with variables which have been significant in former investigations. This problem will be reduced by sequential tests of extended models and alternative assumptions. Another precondition is a multi-normal distribution, but even though the distributions of several variables are skewed, the sample sizes, ranging from 56 to 85 nations, are sufficient to justify the use of product-moment correlations. The statistical programs SPSS 22 and LISREL 9.1 were used for the statistical analyses.

\subsection{Measuring national power distributions}

Manifold instances of equal and unequal power relations exist in politics, economy, and society, as they do in everyday relationships. This fact makes it difficult to measure national power distributions. Electoral systems and other formal institutions which have been used in corruption research (see Treisman, 2007, and his data set) may function in practice quite differently, because they are differently interpreted and enacted. A better way might be 
to represent the daily experiences and interpretations of people with hierarchical institutions by large surveys as in psychological research on culture. Two ways of measuring culture have been practiced, one concentrating on abstract values (e.g. Schwartz, 1992), the other on concrete attitudes (e.g. Hofstede, 2001). House et al. (2004) developed different scales for cultural practices and for cultural values. For predicting national corruption from cultural contexts, the concrete experiences are more appropriate, reflected in attitudes and practices; so we adopt this kind of measurement.

There exist several investigations of the culture-corruption connection. For culture measurement, the Hofstede (2001) scales are most often used, with Power Distance as a measure of social inequality or power distribution as best predictor (Lambsdorff, 2006; Judge et al., 2011). Thus, Power Distance is directly relevant as an operationalization of power distribution, our theoretical concept. Power Distance is defined as "the degree of inequality in power between a less powerful Individual (I) and a more powerful Other (O), in which I and O belong to the same (loosely or tightly knit) social system" (Hofstede, 2001, p. 83, citing Mulder, 1977, p. 90). According to hypothesis 1, national differences in power distributions, measured as daily experiences with Hofstede's Power Distance, should substantially correlate with corruption across countries. All studies that investigated the relation between the Hofstede dimensions and corruption found significant correlations between Power Distance and corruption (Judge et al., 2011). Using the Corruption Perception Index 2010-2012 (CPI; high values mean low corruption) from Transparency International, this expectation was also confirmed in our data with $r=-.67(\mathrm{n}=79)$. Higher Power Distance, measuring a steeper power distribution, is associated with more corruption, as theoretically predicted.

Yet, critics of the Hofstede dimensions, including Power Distance, come to conflicting conclusions (McSweeney, 2002; Ly, 2013). Several features of his methodology are criticized, especially the constitution of the samples and the three Power Distance items. His nonrepresentative samples may be criticized but his specific sampling can also be seen as a strength: His data originated only from IBM employees, making their answers probably quite well comparable across nations, so that differences in mean values between countries really may reveal cultural differences. Moreover, concerning Power Distance, organizations with their hierarchies are probably the best place to really experience social power differences, because people with very different social status belong to the same organization and try to exhibit, advance, or defend their social rank. More convincing is the criticism of only 3 items as a comparative basis across countries:

Item B 46 is calculated as national average of the answers on a 5-point frequency scale to "How frequently, in your experience, does the following problem occur: Employees being afraid to express disagreement with their managers?". Items A 54 and A 55 exhibit lengthy descriptions of four managers with a more or less participatory decision-making style. Then, a national score is calculated from the percentages of a perceived autocratic style (A 55) minus a preferred participatory style (A 54).

As national scores, these items leave much room for interpretations and no reliability can be computed for the combined index. Yet, it seems worthwhile to take up this measure of Power 
Distance and to improve it, because it has fared quite well in research practice by delivering meaningful results, especially in relation to corruption.

In response to the 3-item-criticism, a more reliable and valid comparative measure of power distribution across countries needed to be developed. To raise the reliability and validity of Power Distance as a measure of national power distribution, other culture dimensions were analyzed as possible companions to Hofstede's Power Distance. Candidates were Hofstede's Individualism which loaded with opposite sign on the same factor (Hofstede, 2001, p. 60-63) as well as the seemingly similar Power Distance Practices in the GLOBE study (House et al., 2004). Therefore, through a second order factor analysis of the culture dimensions of Hofstede and the GLOBE practice scales, the convergent and discriminant validity of Power Distance as a measure of national power distribution could be improved. We included the four main dimensions of Hofstede $(2001)^{10}$ and the nine practice dimensions from the GLOBE project (House et al., 2004). These GLOBE data are especially useful as an addition, because the samples, consisting of enterprise employees, are roughly comparable. Hofstede's data was collected between 1967 and 1973, covering 79 countries; GLOBE data was collected between 1994 and 1997, covering 56 countries, including 6 that were not contained in the Hofstede dataset. Van de Vliert's (2013) Freedom Index 2012, which distinguishes freedom securing versus autocratic regimes, was added as the $14^{\text {th }}$ dimension ${ }^{11}$. His data were obtained from 59 countries over a time span from 1946 to 2006. This index added a second measure for 4 of the 6 nations, for which only the GLOBE measure was available. Given that cultures change very slowly, using measurements from different years was deemed to be an acceptable calculation. Based on the country values of these 14 dimensions, a more reliable and valid measure for nations' power distribution could be developed through a second order oblique factor analysis, see the following section.

\subsection{An improved new measure of power distributions}

As argued above, a second-order factor analysis was computed with the 14 cultural dimensions from Hofstede, GLOBE, and Van de Vliert as items. The main result is shown in table 1. Five clearly separable and well interpretable factors emerged; the chosen factor names are easily understandable from their marker items; only the fifth factor, which is used in our model test, needs a thorough interpretation.

Hofstede's Power Distance produced a stable factor together with Individualism from the same author, the Freedom Index from Van de Vliert, and In-Group Collectivism from the GLOBE study (see the rightmost column in Table 1). The three new dimensions, which accompany Power Distance on the 5th factor, allow for a more robust and insightful interpretation of their common variance than each of these variables alone. The following example items of the three new dimensions are helpful for this interpretation (Power Distance items were already cited in 2.1). Hofstede's Individualism items include "Considerable freedom on the job" and "Challenging work for getting a personal sense of accomplishment". GLOBE's In-Group Collectivism includes "In this society, people encourage group loyalty, even if individual goals suffer". Van de Vliert's Freedom Index contains "Freedom from Discrimination", calculated as neighboring with people of other race, immigrants, homosexuals, and criminals (from World Values Survey wave 4, 2004). "Freedom from Press 
Repression", estimated from three sources over three consecutive years and averaged (Van de Vliert, 2011), and "Freedom from Political Autocracy", calculated from 10 different democracy measures (Pemstein, Meserve, and Melton's 2010 Unified Democracy Score). Thus, the Freedom Index combines realizable freedom rights.

Table 1. Results of the factor analysis of 14 culture dimensions $(\mathrm{V}=\mathrm{Van}$ de Vliert, $\mathrm{H}=$ Hofstede, $\mathrm{G}=$ Globe)

\begin{tabular}{|c|c|c|c|c|c|}
\hline Chosen factor label & $\begin{array}{c}\text { Forward } \\
\text { Orientation } \\
3.96\end{array}$ & $\begin{array}{c}\text { Inhumane } \\
\text { Assertive- } \\
\text { ness } \\
1.98\end{array}$ & $\begin{array}{c}\text { Mascu- } \\
\text { linity } \\
1.29\end{array}$ & $\begin{array}{l}\text { Gender } \\
\text { Egali- } \\
\text { tarianism } \\
1.34\end{array}$ & $\begin{array}{c}\text { Power } \\
\text { Balanced } \\
\text { Freedom } \\
3.65\end{array}$ \\
\hline Freedom Index $(\mathrm{V})$ & -.023 & .048 & -.237 & -.033 & .820 \\
\hline Power Distance $(\mathrm{H})$ & -.035 & .003 & -.044 & .049 & -.813 \\
\hline Individualism $(\mathrm{H})$ & -.043 & -.027 & .313 & .130 & .880 \\
\hline Masculinity (H) & -.039 & .070 & .889 & -.079 & .062 \\
\hline Uncertainty Avoidance $(\mathrm{H})$ & -.630 & .293 & -.274 & -.088 & .023 \\
\hline Assertive Practices $(\mathrm{G})$ & .215 & .821 & .257 & .147 & -.088 \\
\hline Institutional Collectivism (G) & .469 & -.437 & -.167 & -.081 & .169 \\
\hline In-Group Collectivism (G) & -.272 & -.007 & .076 & -.157 & -.681 \\
\hline Future Orientation $(\mathrm{G})$ & .882 & .189 & -.083 & .058 & .071 \\
\hline Gender Egalitarianism $(\mathrm{G})$ & -.100 & .126 & -.051 & .904 & .117 \\
\hline Humane Orientation $(\mathrm{G})$ & .076 & -.837 & .161 & .047 & -.141 \\
\hline Performance Orientation (G) & .830 & .082 & .102 & -.341 & .022 \\
\hline Power Distance Practices (G) & -.605 & .209 & .129 & -.356 & .003 \\
\hline Uncertainty Acceptance $^{1}(\mathrm{G})$ & .738 & .061 & -.116 & -.040 & .309 \\
\hline
\end{tabular}

Principal Component Analysis. Explained variance: 75\%. Oblique rotation $(\delta=0)$. Pattern matrix, loadings of marker items are boldface.

As can be seen from the rightmost column in Table 1, high Power Distance (- sign) is incompatible with Freedom from political autocracy, repression of deviant opinions, and discrimination (+ sign). In more egalitarian societies, individual freedom rights can be more safely used, because they are collectively protected against autocracy, repression, and discrimination. These Freedom aspects $(+)$ are connected to Individualism (+), which is also opposed to Power Distance (-). Hofstede's Individualism was sometimes equated with egoism, but the items and the negative relation between Freedom and Power Distance show that Hofstede's Individualism has nothing to do with Egoism, it is about individual autonomy. Individualism (+) contrasts with In-Group Collectivism (-), which suggests that people can experience autonomy, relatively unrestricted by group pressures. Low Power Distance (-) goes together with high Individualism $(+)$ which both are necessary for controlling those in power instead of being overpowered. Finally, high In-Group Collectivism provides the theoretically expected justification for powerholders to use restrictive control as corruption and exploitation of out-group others. Privileging one's extended family or ethnic or religious in-group members is 'normal' behavior.

1 The GLOBE authors called this dimension "Uncertainty Avoidance", as did Hofstede, but as judged from their opposite signs and the high relation of the GLOBE measure to Future Orientation and Performance Orientation, apparently higher values mean "uncertainty acceptance" and therefore it was renamed. 
Combining, standardizing and averaging Power Distance (reverse scored), Individualism, In-Group Collectivism (reverse scored), and realizable Freedom Rights into a common index represents the essence of this fifth factor ${ }^{12}$. We will label this new index "Culture of Freedom through Power Balance" or as a short form "Power Balanced Freedom" (abbreviation: PBF). The name of this new index highlights the cultural connection between the power distribution and the freedom situation within societies: Realizable freedom can only flourish if power balance prevails; a steep power distribution impairs elementary freedom practices. It is a central principle of democracy that civil rights and checks and balances are conditioning each other. So, necessary for using basic freedom rights as promised in UNO's declaration of human rights is the social, political and economic balance of power. Van de Vliert's Freedom Index also contains these elements, formulated as freedom from undue dominance.

PBF has an improved validity, compared with Power Distance alone: At the societal level, the extent of power distribution is strongly connected to low freedom opportunities; they condition each other and are opposing ends of the same cultural essence. This content and convergent validity of higher power distribution with lower freedom is supported by discriminant validity through a clear differentiation from the other four factors. The empirical suitability of this new PBF factor is strengthened by high reliability (Cohen's $\alpha=.93$ ). Finally, construct validity can be demonstrated through the predicted relation to corruption. Using the Corruption Perception Index (CPI) 2010-2012 from Transparency International (high values mean low corruption), PBF correlates strongly $(r=.78, \mathrm{n}=85)$ with low Corruption, whereas Hofstede's Power Distance alone has a lower correlation $(r=-.67, \mathrm{n}=$ 79). The spread of PBF from autocratic to deeply democratic countries together with CPI is illustrated in figure 3. Like the more basic distinction between promotive and restrictive control, discussed above, high versus low Power Balanced Freedom has direct ethical relevance, which will be explored in section 4.5 .

\subsection{Operationalization of the other model variables}

Corruption. For measuring the national degree of corruption, the Corruption Perception Index (CPI) from Transparency International was used. Although there is little change in this index from year to year, data from 2010, 2011, and 2012 was averaged to raise reliability. CPI is the most often used index, despite some criticism. Although the index lacks details as an overall multiple source estimate, it has been refined over the years (Lambsdorff and Schulze, 2015; Rose-Ackerman and Palifka, 2016). It correlates most highly with other corruption measures, indicating the highest concurrent validity (Judge et al., 2011). One unresolved problem of CPI, however, was elaborated by Johnston (2014) who distinguishes four syndromes of corruption. One of the four, Influence Markets, typical for western democracies, is not represented in the CPI values, because businesses, wealthy individuals, and well-funded interest groups have legal means to influence politics to privilege their special interests (well documented for the USA by Stiglitz, 2012). These legal means for getting undeserved advantages are not sufficiently represented in the CPI, nor in any other index. Thus, they could not be included in our data. 


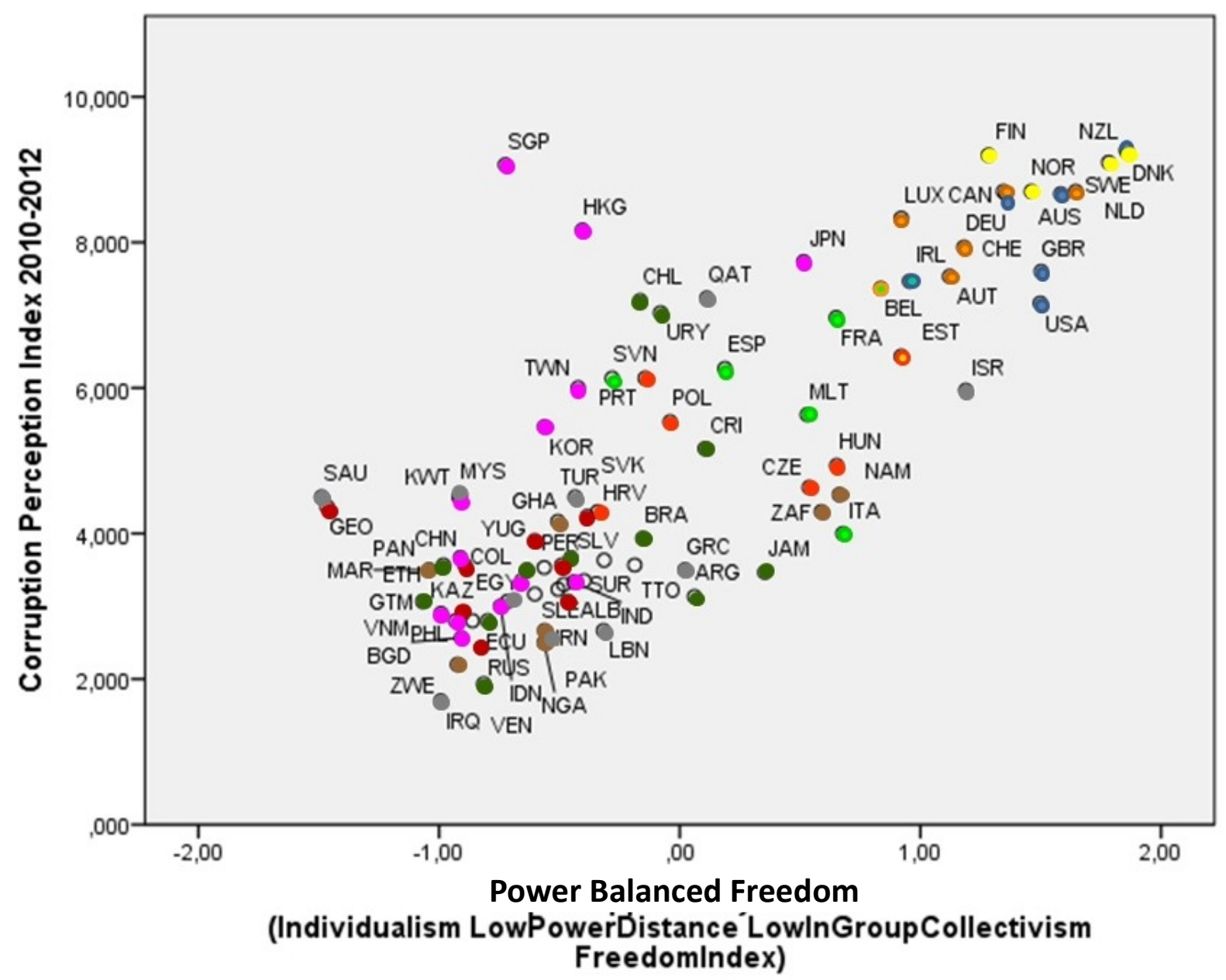

Figure 3. Distribution of countries along Power Balanced Freedom and Corruption.

Note. Country groups are differentiated by color. Yellow dots are Scandinavian countries, blue Anglo-Saxon, orange Germanic, light green Romanic, dark green South American, lilac Asian, light red former socialist middle European, dark red former Socialist Balkan and Soviet Union, brown African, and grey former Osmanic countries. Some country names were omitted by SPSS.

Gross Domestic Product. GDP is the most common measure for comparing the economic success of nations, calculated per capita in current prices in U.S. Dollars. Data for 2010-2012 was extracted from the International Monetary Fund (2013) website and averaged.

Inequality-adjusted Human Development Index. The IHDI combines inequalityadjusted data for life expectancy, education (years of schooling), and income. Data for 2010, 2011, and 2012 was extracted from the United Nations Development Program (2014) and averaged. Inequality-adjusted Human Development Index is a very abstract name; its content could also be expressed as 'widely shared life chances'. We prefer the IHDI as an objective indicator of well-being to the often discussed and broadly researched subjective variable happiness, because happy feelings over time raise one's aspiration level so that objectively similar events over time evoke less subjective happiness (March and Simon, 1958). Thus, different objective conditions might get the same subjective evaluation.

Trade Openness. To be able to predict GDP independently from corruption, data on Trade Openness (Mean Imports as \% of GDP 2010-2012) was extracted from the World Bank 
(2016). Although seemingly unusual (Aidt, 2011; Johnston, 2014), the Trade Openness values were additionally divided by the number of the country's inhabitants, because smaller countries typically have to import more goods and services than larger countries.

Human Capital. Data on Human Capital, operationalized as educational resources, was imported from Hanushek and Woessmann (2012), especially the share of top-performing students (average test scores in math and science from primary to the end of secondary school, all years). This measure fared better in their analyses than the more usual average years of schooling in a country.

Former Colonial Status. Obtained from a dataset from Treisman (2007), Former Colonial Status was used for GDP prediction in line with his results. Colonialism brought an additional political and economic disadvantage for these countries (Acemoglu and Robinson, 2012) by introducing strange political and economic systems. With liberation, colonialism handed over excessively hierarchical models of administration which eased vesting enormous powers in a single hand (Everett et al., 2007).

Finally, data on other potentially relevant variables, collected by Treisman (2007) for his review of empirical corruption research, were used for several checks on possible alternative interpretations.

\section{Results}

The relevant means, standard deviations, and correlations of the variables used for estimating our model are shown in Table $2^{13}$.

Table 2. Model variables with means (M), standard deviations (SD), number of countries (N), and correlations.

\begin{tabular}{|c|c|c|c|c|c|c|c|c|c|c|}
\hline Variable & M & SD & $\mathrm{N}$ & 1 & 2 & 3 & 4 & 5 & 6 & 7 \\
\hline 1 Power Balanced Freedom & -.04 & .87 & 85 & & & & & & & \\
\hline 2 Gender Egalitarianism & 3.38 & .36 & 56 & .29 & & & & & & \\
\hline 3 Never a Colony & 0.22 & .42 & 85 & .24 & .09 & & & & & \\
\hline 4 Trade Openness & 12.7 & 42.5 & 76 & .16 & .14 & -.14 & & & & \\
\hline 5 Top Share M\&S Stud. & .06 & .05 & 60 & .50 & .07 & .19 & .09 & & & \\
\hline 6 Low Corruption 2010-12 & 4.99 & 2.20 & 85 & .78 & .20 & .25 & .21 & .69 & & \\
\hline 7 GDP per Person 2010-12 & 11 mio & $11 \mathrm{mio}$ & 85 & .69 & .18 & .28 & .38 & .57 & .82 & \\
\hline $\begin{array}{l}8 \text { Inequality adj. Human De- } \\
\text { velopment Index 2010-12 }\end{array}$ & 618 & 183 & 74 & .69 & .37 & .28 & .20 & .77 & .76 & .73 \\
\hline
\end{tabular}

As questioned in figure 2, the other four culture factors (cf. table 1) could not increase the prediction of Corruption besides PBF. Therefore, they were omitted from further analyses (and from table 2). Yet, the culture dimension Gender Egalitarianism (cf. table 1) was an additional significant predictor of IHDI and is included in table 2. As a next step, Human 
Capital as measured with Top Share of Math \& Science Students had to be omitted as well, because it did not add a significant portion to the explanation of GDP. The same happened with the alternative measure Mean Years of Schooling. So, hypothesis 6 is refuted.

The adapted path model, estimated with LISREL 9.1, showed a statistically almost perfect model fit: Data do not significantly deviate from the theoretical model, $\mathrm{p}=.36$, $\mathrm{RMSEA}=.03, \mathrm{SRMR}=.04, \mathrm{CFI}=1.00, \mathrm{NFI}=.98$. All hypotheses except H6 are confirmed. Yet, there is one additional critical point: The feedback effect of GDP on Corruption is almost zero $(p=-.02)$ and not significant $(t=-.12)$. Although this is grossly in line with $H 3$, that the feedback effect is lower than the Corruption-lowers-GDP effect, this path should not be retained in the model ${ }^{14}$. Doing this gives a very similar and slightly better final estimation, shown in figure 4.

This model raises the causal test power to eight degrees of freedom instead of none for regressions, which means that the eight correlations between those exogenous and endogenous variables, that are not directly connected in the model and set to zero, must be according to the central path theorem - approximately in line with the logically implied mediation effects and the respective indirect numerical values. As a further strength of this model, the main variables PBF, CPI, GDP, and IHDI originate from quite different sources: PBF is mainly a psychological variable derived from employee surveys, CPI a politicoeconomic variable based on expert estimations, GDP an economic and IHDI a societal variable, both measured by different methods in national statistics bureaus. There is probably no common method variance such that the danger of correlated errors is much lower, and if so, they would have been detected by the path analytic program. Multicollinearity between the exogenous variables is very low, the strongest correlation is .29 between the two equalityoriented cultural factors Power Balanced Freedom and Gender Egalitarianism.

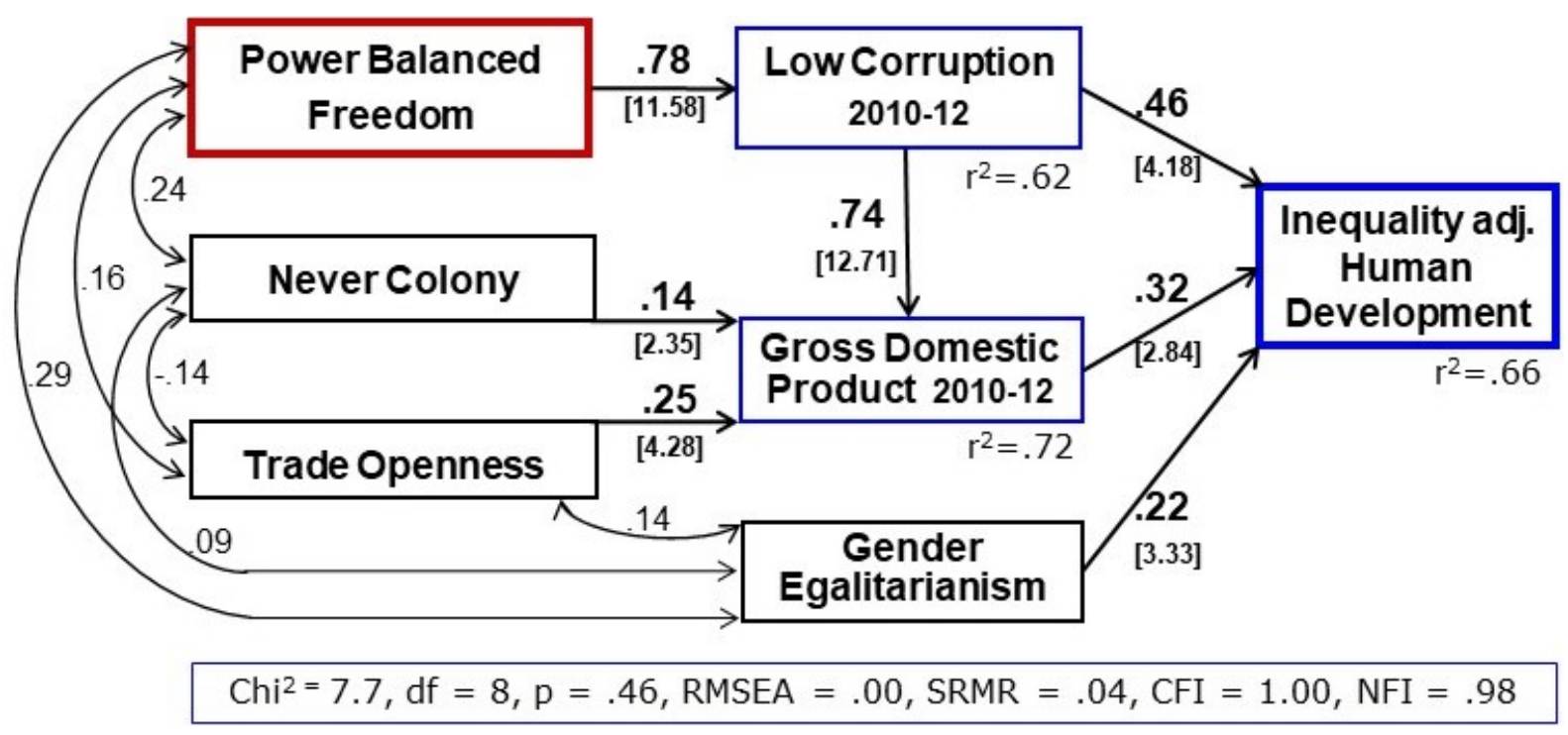

Figure 4. Final path model of the causes and consequences of corruption.

Note. Values on double-headed arrows are correlations between the exogenous variables, numbers on directed arrows are path coefficients (= standardized partial regression coefficients) with t-values in brackets below; $\mathrm{r}^{2}$ below the endogenous variables are adjusted explained variances. 
The following aspects of these model estimates are especially noteworthy:

(1) Power Balanced Freedom explains $62 \%$ of national differences in corruption. The other four cultural factors (see Table 1) failed to explain additional variance in corruption, although other Hofstede and GLOBE dimensions have been found as predictors in former studies (Akbar and Vujić, 2014; Cheung and Chan, 2008; Husted, 1999; Mensah, 2014). This discrepancy is most likely due to the integration of four important culture dimensions in our composite index PBF, as well as its higher reliability and validity.

(2) Several other commonly reported predictors for corruption, mainly from Treisman's (2007) dataset, were tested, including several indices for religious denominations and for women in higher positions, number of armed conflicts, former communist reign, continent dummies, and climatic demands. None could explain additional variance. The same holds for political rights, institutional democracy score, democratic tenure, and press freedom, partly because the Freedom Index in PBF includes some of these aspects ${ }^{15}$. PBF seems to be the most relevant and robust factor with regard to corruption.

(3) No reverse effect of GDP on CPI could be found. The path coefficient was not significant, almost zero $(-.02, \mathrm{t}=-.12$, see Figure $\mathrm{S} 1)$. This is all the more remarkable because some authors judge the GDP-on-CPI effect to be the main one (see the discussion in 1.3).

(4) GDP 2010-2012 could be explained to a large extent by CPI 2010-2012 with a path coefficient of .74, additionally by Trade Openness (.25) and if country was Never a Colony (.14). Together, $72 \%$ of national differences in GDP are explained.

(5) Low corruption had the strongest direct effect on IHDI (.46), interpreted as widely shared life chances. GDP's effect was .32, and Gender Egalitarianism, another separate culture variable, added a path of .22. Together, they explained $66 \%$ of national differences in IHDI. The strong effect of low corruption on IHDI can be interpreted as exertion of less restrictive control, promoting better public knowledge production and better decisions and thereby improving IHDI. Corruption seems to be the tip of an iceberg: Hidden below the waterline, there is the totality of restrictive versus promotive control incidents in all spheres of society.

(6) The total effect of PBF on IHDI via CPI and GDP is .54, which is larger than each of the direct predictors. The theoretically derived effect is fully confirmed: The steeper the culturally ingrained power distribution, accompanied by less individual freedom, the more corruption, is induced, with lower GDP and IHDI as important socioeconomic consequences.

(7) Contrary to Hanushek and Woessmann (2012), Human Capital (top share of math and science students) added nothing to explain GDP, despite the high correlation of .57. The same holds for their other Human Capital proxy: Average Years of Schooling. According to the theoretical arguments above, corruption as restrictive control impairs knowledge production and effectiveness. Therefore, the reverse seems to be valid, a negative effect of corruption on Human Capital, a proxy for knowledge production. This is confirmed by an additional analysis ${ }^{16}$ as well as by mean years of schooling as part of IHDI.

(8) Three of the four exogenous variables, PBF, Gender Egalitarianism, and Former Colonial Status are culture variables. Only Trade Openness is a pure economic variable. Hence, culture appears to be very important in the context of corruption. One could object that 
the Freedom Index as part of PBF contains political autocracy and press freedom as institutional, not cultural aspects. Yet, when the Freedom Index is omitted from PBF, the path to Corruption is barely reduced from .78 to .74; all other paths remained identical and the relevant test indices differed only in the third digit. Institutional aspects are not independent from culture, they are rather differently interpreted and practiced according to people's cultural horizon.

\section{Discussion}

Based on a psychological theory of the corrupting effect of unequal power distributions and an appropriate culture measure PBF, we tested a complex model on the cause and effects of corruption with a nonrecursive path analysis. The strength of this approach can well be demonstrated by relating it to a recent research summary (RoseAckerman and Palifka, 2016, p. 28), which is depicted in figure 5.

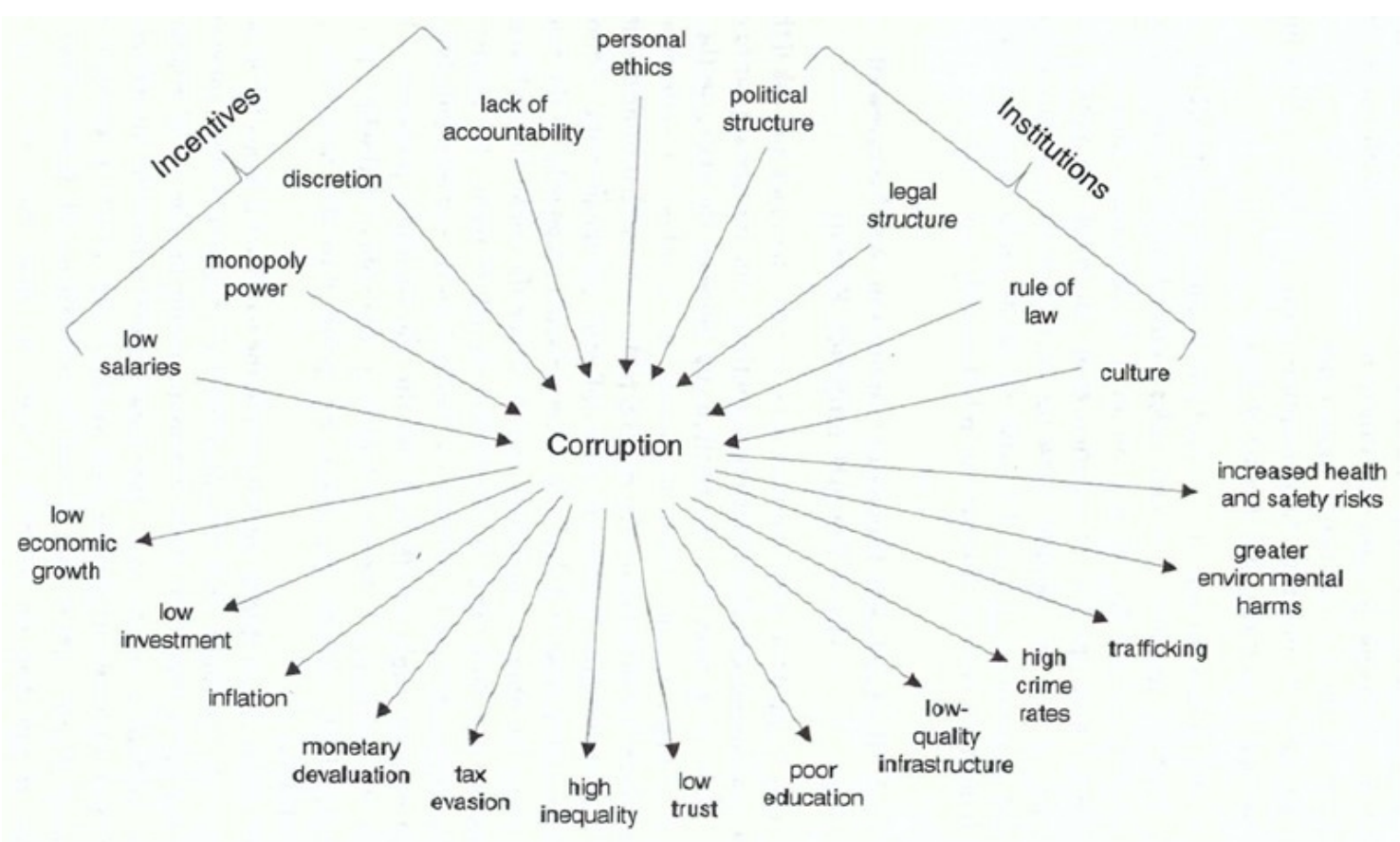

Figure 5.

Causes and consequences of corruption (from Rose-Ackerman and Palifka, 2016, p. 28)

\subsection{Causes of Corruption}

In the upper left of figure 5, monopoly power, discretion, and lack of accountability are mentioned as incentives for corruption. All three are typical aspects of unequal power distributions, and many more instances may exist in a society. It would be difficult to grasp these and other occurrences in detail, but the encompassing PBF measure gives an overall estimate, which includes the copious experiences of Power Distance, Political Autocracy, Press Repression, Discrimination, and In-Group Collectivism as well as low Individualism, that is, a lack of rights, of freely expressing opinions and of following own interests. Culture 
is not a separate entity, distinct from these three incentives for corruption; it rather seems to summarize the meaning of them, as measured by PBF.

The same argument holds for the institutional causes on the upper right of figure 5. The political and legal structure of a country can be described and analyzed from many sources, but the collective interpretations of these realities by the citizens of the country are vital, and they may well be tapped by the PBF measure. Variables that portray the political and legal structure, such as the "Institutionalized Democracy Score" or the "Tenure of the Democratic System" (Data from Treisman 2007), correlate highly with corruption (.49 and .70 respectively) but even higher with PBF (.62 and .78). Their structure seems to be included in the PBF measure to the extent that they could not explain any additional variance. This result reflects the meaning of $\mathrm{PBF}$ as going beyond the formal existence of democratic institutions.

Rule of Law is often considered as predictor of corruption (see Figure 6), but the high correlation between the two variables $(r=.995)$ suggests that Rule of Law is not a variable logically independent from Corruption but just the other side of the coin. That is, high Corruption implies that Rule of Law is ineffective and if Rule of Law is well functioning, Corruption must be low. Moreover, substituting Rule of Law for PBF in the model led to irregular path coefficients much larger than 1.0.

Cultural influences on corruption have often been investigated with percentages of women in occupational positions, a proxy measure for female influence. As a genuine culture variable that taps the gender aspect more deeply, Gender Egalitarianism at first seemed to be part of PBF, but statistically it emerged as a distinct factor (see Table 1). It is also not an additional predictor of corruption, but of IHDI, which suggests that a culture of Gender Egalitarianism is directly relevant for politics. Percentages of religious membership in the countries is a very formal variable, disguising large cultural differences within the world religions. Even percentages of protestants, which correlate significantly with lower corruption, could not persist as an additional predictor beneath PBF.

Personal ethics is depicted as another cause of Corruption in Figure 5, but country differences must be explained by collective morals. In-Group Collectivism as part of PBF seems to be such a collectively shared justification for Corruption (e.g., "We have to care for our group"). Rose-Ackerman and Palifka (2016) explained this phenomenon by social norms in many African and Asian countries:

"The political powerful are expected to receive tribute from their subjects. If politicians or public officials have the opportunity to enrich themselves, they have an obligation to do so and to share generously with those who helped them to advance. ... Ordinary people condemn corruption at the elite level, but they participate in networks that socially reproduce corruption.... Ethnographic research tends to concentrate on cultural and social expectations to explain the prevalence of personalistic ties and quid pro quo transactions, but these interactions are also tied to the bargaining powers of officials" (pp. 264-266). 
This statement was confirmed on a general level by the combination of Power Distance and In-Group Collectivism in our PBF measure. In sum, PBF summarizes most of the causes of corruption as illustrated in Figure 5, and it predicted $62 \%$ of the national differences in Corruption.

\subsection{Consequences of Corruption}

Low economic growth is one of the consequences of corruption in figure 5, and - as expected - Corruption had a strong negative path coefficient on GDP with $.74(\mathrm{r}=.82)$. Yet, no feedback effect from GDP on corruption was found, contrary to some expectations (RoseAckerman and Palifka, 2016) or even opposite GDP $\rightarrow$ Corruption assumptions (Akbar and Vujić, 2014; Cheung and Chan, 2008; Husted, 1999; Treisman, 2007; see the overview in Judge et al., 2011). However, if more predictors of GDP could be found that add variance unexplained by corruption and have low collinearity with PBF, then a small feedback effect might show up. Proposed candidates, such as the share of top math \& science students or mean years of schooling as proxy measures for Human Capital (Hanushek and Woessmann, 2012), could not be substantiated as affecting GDP. Instead, the findings and interpretations of Mauro (1998) are confirmed that corrupt societies are less inclined to broadly invest in human capital.

The Inequality-adjusted Human Development Index (IHDI) includes three further consequences of corruption which are illustrated in Figure 5: increased health and safety risks are included in average life expectancy, low education is well measured by average years of schooling, and low salaries are directly related to average income. The latter appears in Figure 6 as a cause which would imply a feedback effect of GDP on corruption which was not found. These three measures are adjusted for inequality, a further consequence shown in Figure 5. Overall, our model predicts very important consequences of Corruption, explaining $72 \%$ of GDP and $66 \%$ of Inequality-adjusted Human Development.

Two articles on culture and corruption from this journal are also relevant for comparisons, Jing and Graham (2008) and Lopez and Santos (2014). The first used a similar culture index, containing the two Hofstede dimensions Power Distance and Individualism, and a similar structural equation approach, but with latent variables. Different from our results, GDP as part of their economic development index is seen as directly dependent on culture, not indirectly as in our model, and there is no causal relation from corruption to economic development including GDP. Yet, GDP is combined with economic freedom and a market structure index in their economic development index, i.e. a well-confirmed consequence, GDP, is combined with institutional predictors of (low) corruption (e.g. Lopez and Santos, $2014^{17}$; for an overview cf. Rose-Ackerman and Palifka, 2016). Thus, any causal relation between corruption and GDP will be obscured.

Lopez and Santos (2014) also use Hofstede's Power Distance and Individualism as predictors of corruption, add different forms of trust as proxies for social capital and an institutional 'Global Economic Freedom Index' (details are not reported) in an analysis of 60 nations. Except trust, these are similar to our composite measure and they are all significant predictors in a regression analysis. Since only unstandardized regression-coefficients are 
reported, the relative strength of the predictors remains unknown, but the authors report that "the power-distance cultural dimension has the highest explanatory capacity." (p. 706). They conclude: "Corruption is clearly explained by a sociocultural substrate that we have denominated culture of dependency" (p. 706). This is generally in line with our analysis which goes two steps further by putting the explanation of corruption into a complex model with two important consequences of corruption.

\subsection{Culture or institutions as main cause of corruption?}

While our analysis and other cited articles see culture as an important cause of the extent of national corruption, influential economists judge it to be of minor relevance. This was already discussed with regard to Rose-Ackerman and Palifka (2016) and it will be deepened with regard to the widely praised case studies of Acemoglu and Robinson (2012) about the economic failure of nations. Our above developed causal model could, indeed, also be understood as an explanation of the failure of nations. In their analysis, failure is engendered by extractive political and economic institutions, whereas inclusive institutions foster economic success. Central for their argumentation is the corrupting effect of a dictatorial or oligarchic power distribution:

"Nations fail economically because of extractive institutions. ... In all these cases the basis of these institutions is an elite who design economic institutions in order to enrich themselves and perpetuate their power at the expense of the vast majority of people in society." (pp. 398-399) "Pluralism, the cornerstone of inclusive political institutions, requires political power to be widely held in society" (p. 458).

This is quite in line with our analysis: Enrichment of an elite by means of corruption is upheld by a steep power distribution which causes the economic failure of nations as measured by GDP. "Pluralism, ... political power to be widely held in society" respectively Power Balance as measured by PBF is the appropriate basis for a thriving economy. Yet, the authors reject the role of culture as an explanation of economic differences, because they accept the usual, but inadequate understanding of culture:

"The culture hypothesis relates prosperity to culture. ... Is the culture hypothesis useful for understanding world inequalities? Yes and no. Yes, in the sense that social norms, which are related to culture, matter and can be hard to change, and they also sometimes support institutional differences, this book's explanation for world inequality. But mostly no, because those aspects of culture often emphasized - religion, national ethics, African or Latin valuesare just not important for how we got here and why the inequalities in the world persist. Other aspects, such as the extent to which people trust each other or are able to cooperate, are important but they are mostly an outcome of institutions, not an independent cause." (pp. 56-57)

Religions per se, of course, are not well suited as an explanation because they are all differently influenced by their cultural environment, and thus one cannot sufficiently signify nations as Protestant, Catholic, or Buddhist culture. For example, U.S. Evangelicals differ 
very much from German Protestants, and Brazilian Catholics differ considerably from Austrian Catholics. The latter probably have much more in common with German Protestants because of their common language and interwoven history. The same holds for African and Latin values where large differences exist within these clusters (Inglehart and Baker, 2000). Acemoglu and Robinson's (2012) statement about trust lacks evidence for their causal assumption that institutions are primary and that trust is an outcome of them. Guiso et al. (2016) directly refuted Acemoglu and Robinson (2012) with an Italian example of long-term cultural persistence of social capital, a proxy to trust, despite institutional changes. Most probably, trust and institutions are mutually interdependent societal aspects (Rothstein and Uslaner, 2005). This holds as well for culture and institutions in general (Alesina and Giuliano, 2014).

The evidence in the social sciences speaks for persistent mutual influences between mental and material aspects of perceived and enacted reality. Like any other facts and formal arrangements, the functioning of institutions is shaped by cultural interpretations and vice versa (Alesina and Guiliano, 2014; Berger and Luckmann, 1966; MacKinnon and Heise, 2010). The old wisdom of the so-called Thomas-theorem should be taken seriously: "If men define situations as real, they are real in their consequences" (Thomas and Thomas, 1928, p. 572), which suggests that institutional schemes, per se, do not affect behavior, but rather an experienced institutional reality shaped by ideas and interpretations.

The above developed measure of PBF includes such daily life experiences and their cultural interpretation, gained from opinion surveys, as well as a mix of cultural and institutional estimates within the Freedom Index. This compound national culture index is well suited to explain quantitative differences in Corruption, GDP, and Inequality-adjusted Human Development. The PBF construct is much more fine-grained than the dual classification into extractive and inclusive institutions by Acemoglu and Robinson (2012). This reality of cultural differences beyond formal institutions is especially well observable between Scandinavian, Germanic, and Romanic countries in Europe. These countries form separate clusters with different language roots reaching far back in history, and they exhibit remarkable differences in PBF as well as Corruption (see figure 2). Yet, their formal political and economic institutions, affiliated with the European Union, are very similar.

Our emphasis on the importance of cultural guidelines, experiences, and practices does not weaken the conclusions of Acemoglu and Robinson (2012), which are backed by impressive case studies of institutional developments in diverse countries. Quite the contrary, our analysis may be understood as a quantitative specification of the logic behind their many concrete examples of what to avoid and how to proceed into a more inclusive, power balanced, free, and prosperous direction.

\subsection{Limitations}

As in every empirical study, there are some limitations. Many smaller countries are not represented in the dataset. Nevertheless, the number of included countries is larger than that of most other culture and corruption studies, and they represent $86 \%$ of the world's population of 2011. Some variables also had missing values and the correlations were 
calculated pairwise so that some of the correlations amounted to less than 85 countries (see Table 2). To evaluate this problem, mean values of the respective country groups were entered for these variables, and the dataset was re-analyzed. The model is equally well confirmed, only the path coefficients and the associated explained variances are slightly lower than in the analysis above (see fn 15).

One limitation is that Hofstede's and GLOBE's dimensions were created from survey data collected many years ago. Of course, cultural change is slow and changes in the dimensions themselves are presumably much slower. Nevertheless, newer data would be worthwhile for a replication study. Another limitation pertains to one aspect of the Corruption Perception Index (CPI) of Transparency International. On the one hand, it seems to be the best available measure of corruption with highest concurrent validity (Judge et al., 2011). CPI, however, does not include the legal corruption of influence markets as Johnston (2014) emphasized. To augment CPI in this respect would be extremely worthwhile and would probably further differentiate several democracies. In a similar vein, IHDI does not include negative external effects on the environment that would provide a more appropriate picture of real well-being within a society. Finally, the hypotheses and the whole model structure contain complex causal assumptions which were largely confirmed in the path analytic test; only hypothesis 6 failed. But even the near perfect final test, depicted in figure 4, cannot exclude that eventually other models with different variables and causal assumptions may be similarly well confirmed.

\subsection{Ethical reflections}

Promotive and restrictive control in general, Power Balanced Freedom as their differing mix on the cultural level in particular, as well as the whole confirmed model of the causes and consequences of corruption have direct ethical relevance. As said above, promotive and restrictive control are distinguished by respecting versus violating the autonomy of the persons concerned. Since restrictive control treats others as a means to own ends, it is incompatible with Kant's categorical imperative. The ethical basis of moral action is autonomy, i.e. the freedom to be able to decide between more or less moral acts. To deny others this freedom by using restrictive control, and at the same time requiring it for oneself, is logically inconsistent as an ethical principle and thus not justifiable (Pieper, 2017). From that it follows for human practice: "A human being cannot be free alone. Freedom is only possible under the condition that one's freedom is open to others' freedom" (Krings, 1980, p. $125)^{18}$. For the use of power, the following can be derived in line with our definition of promotive control: "The person who uses power over others has to do that to the best of one's knowledge and in all conscience for their well-being. i.e. to fend off harm from them. He or she is ethically obliged, to consider the interests of the entrusted and to use his or her power in such a way that the actual or potential autonomy is respected (Pieper, 2005, p. 4) ${ }^{19}$.

This reflection can be extended to whole societies. They should be organized in such a way that as many people as possible are encouraged to, and do, enjoy the largest freedoms possible without violating others' freedom. In line with these considerations, article 1 of the universal declaration of human rights proclaims: "All human beings are born free and equal in 
dignity and rights. They are endowed with reason and conscience and should act towards one another in a spirit of brotherhood." (United Nations, 1948). The meaning of article 1 is substantiated in the following articles 2-30. Our new measure of Power Balanced Freedom can be seen as reflecting how far article 1 and the following special freedom articles are observed in different nations. At the same time, PBF reminds us that the chances for the realization of article 1 and the other freedom articles depend on one's country's power distribution.

The confirmed model of the causes and consequences of corruption (see figure 5) highlights the promises of realizing the broadest freedom opportunities in line with Kant's categorical imperative and the universal declaration of human rights. The more a "Culture of Freedom through Power Balance" is in effect, the higher are - with relative high probability GDP and IHDI. Perhaps most interesting from an ethical point of view is the reconciliation of Kant's deontological approach with utilitarian or consequentialist approaches in practice: Respecting and securing everyone's Power Balanced Freedom (high PBF) as ethical basis is in its consequences compatible with utilitarian approaches of the largest benefit for the largest number of people, as measured by Inequality-adjusted Life Expectancy, Education, and Income (IHDI). Thus, our confirmed causal model of the cause and the consequences of corruption quite well reflects the extent of realizing Rawls' principles of justice: His "greatest equal liberty principle”, in line with Kant's categorical imperative, reads: “(a) Each person has the same indefeasible claim to a fully adequate scheme of equal basic liberties, which scheme is compatible with the same scheme of liberties for all". His difference principle, which is by and large in line with Popper's (1945, pp. 284-285) "minimize pain" utilitarianism, reads "(b) Social and economic inequalities ... are to be to the greatest benefit of the least-advantaged members of society (the difference principle)" (Rawls, 2001, p. 42). Economic interest groups and political parties, especially so-called populist ones, as well as ordinary citizens often tend to compromise universal freedom and justice principles for ostensible economic or political advantages. This might be true or wrong, but it is most probably wrong in a longer historical perspective, as our model and many historical examples suggest.

\section{Conclusion}

Culture as guidelines for human thoughts, feelings, and actions influences many institutional structures and societal processes of a nation. As shown above, the three culture variables PBF, Gender Egalitarianism, and Former Colonial Status can explain most of the variance of corruption and its consequences - when appropriately measured. The newly developed dimension, Power Based Freedom, was derived from a strong theoretical and empirical base of the friendly or hostile uses of power, i.e. of promotive and restrictive control, where the latter becomes more likely with a steeper power distribution. Its four components, Individualism, low Power Distance, realizable Freedom, and low In-Group Collectivism have an affinity to the declaration of universal human rights, but additionally emphasize power balance as precondition. The theoretical concepts of promotive and restrictive control, the empirically validated measure PBF, and the whole model of the causes and consequences of corruption can immediately be matched with basic ethical principles. 
PBF and its consequences for Corruption, GDP, and IHDI also fit well to the theory and case studies of Acemoglu and Robinson (2012), augmenting their results with quantitative detail and clarity. Culture as the everyday experience and interpretation of institutional regularities proved to be a better predictor of corruption than several formal institutional indicators. For all nations, regardless of the actual corruption level, much can be gained by proceeding in the direction of high PBF: Progress will be made by diminishing power differences, by enlarging individual freedom in daily practice, by promoting the acceptance that other individuals have the same freedom rights instead of privileging one's in-group, and by better controlling superior powers in society, economy, and polity.

\section{References}

Abele, A. E., \& Wojciszke, B. (Eds.). (2013). Special issue: The big two in social judgment and behavior. Social Psychology, 44, 61-176.

Acemoglu, D., \& Robinson, J. A. (2012). Why nations fail. The origins of power, prosperity, and poverty. Crown - Random House, New York, NY. ISBN: 978-0-307-71921-8

Aidt, T. S. (2011). Corruption and Sustainable Development. In S. Rose-Ackerman \& T. Søreide (Eds.), International handbook on the economics of corruption (vol. 2, pp. 351). Elgar, Cheltenham, UK.

Aidt, T., Dutta, J., \& Sena, V. (2008). Governance regimes, corruption and growth: Theory and evidence. Journal of Comparative Economics, 36, 195-220. doi: 10.1016/j.jce. 2007.11.004

Akbar, Y. H., \& Vujić, V. (2014). Explaining corruption. The role of national culture and its implications for international management. Cross Cultural Management, 21, 191-218. doi: 10.1108/CCM-03-2013-0050.

Alesina, A., \& Giuliano, P. (2015). Culture and institutions. Journal of Economic Literature 53, 898-944. doi: 10.1257/jel.53.4.898.

Bagozzi, R. P., \& Yi, Y. (2012). Specification, evaluation, and interpretation of structural equation models. Journal of the Academy of. Marketing Science, 40, 8-34. doi: 10.1007/s11747-011-0278-x

Baldwin, J. N., Borrelli, S. A., \& New, M. J. (2011). State educational investments and economic growth in the United States: A path analysis. Social Science Quarterly, 92, 226-245.

Berger, P. L., \& Luckmann, T. (1966). The social construction of reality. Doubleday, Garden City, NY.

Blalock, H. M. Jr. (Ed.). (1971). Causal models in the social sciences. Chicago, IL: AldineAtherton.

Buschmeier, U. (1995). Macht und Einfluss in Organisationen [Restrictive and promotive control in organizations]. Cuvillier, Göttingen, Germany.

Chen, S., Lee-Chai, A. Y., \& Bargh, J. A. (2001). Relationship orientation as a moderator of the effects of social power. Journal of Personality and Social Psychology, 80, 173-187. doi: $10.1037 / / 0022-3514 . S 0.2 .173$ 
Cheung, H. Y., \& Chan, A.W. H. (2008). Corruption across countries: Impacts from education and cultural dimensions. The Social Science Journal, 45, 223-239. doi: 10.1016/j.soscij.2008.03.002.

Cialdini, R. B. (1993). Influence: Science and practice ( $3^{\text {rd }}$ ed.). New York: HarperCollins. Dalberg-Acton, J. E. E. (1907). Historical essays and studies (ed. by J. N. Figgis \& R. V. Laurence). Macmillan, London, UK. Cited from https://de.wikipedia.org/wiki/John Emerich_Edward_Dalberg-Acton,_1._Baron_Acton.(accessed September 11, 2016.)

Duncan, O. D. (1966). Path analysis: Sociological examples. American Journal of Sociology, $72,1-16$.

Duncan, O. D., Haller, A. O., \& Portes, A. (1971). Peer influences on aspirations: A reinterpretation. In H. M. Jr. Blalock (Ed.), Causal models in the social sciences (pp. 219-244). Chicago, IL: Aldine-Atherton.

Etzioni, A. (1968). The active society. A theory of societal and political processes. New York: The Free Press.

Everett, J., Neu, D., \& Rahaman, A. S. (2007). Accounting and the global fight against corruption. Accounting, Organizations and Society, 32, 513-542. doi: 10.1016/j.aos.2006.07. 002.

Georgesen, J. C., \& Harris, M. J. (1998). Why's my boss always holding me down? A metaanalysis of power effects on performance evaluations. Personality and Social Psychology Review, 2, 184-195. doi: 10.1207/s15327957pspr0203_3.

Guiso, L., Sapienza, P. \& Zingales, L. (2016). Long-term persistence. Journal of the European Economic Association, 14, 1401-1436. doi: 10.1111/jeea.12177.

Hanushek, E. A. \& Woessmann, L. (2012). Do better schools lead to more growth? Cognitive skills, economic outcomes, and causation. Journal of Economic Growth, 17, 267-321. doi: 10.1007/s10887-012-9081-x.

Heine, S. J. (2012). Cultural psychology (2 $2^{\text {nd }}$ ed.). New York: Norton.

Hofstede, Geert. (2001). Cultures's consequences. Comparing values, behaviors, institutions, and organizations across nations (2nd ed.). Sage, Thousand Oaks, CA.

House, R. J., Hanges, P. J., Javidan, M., Dorfman, P. W., \& Gupta, V. (Eds.). (2004). Culture, leadership, and organizations: The globe study of 62 societies. Sage, Thousand Oaks, CA.

Hoyle, R. H. (2012). Path analysis and structural equation modeling with latent variables. In American Psychological Association, APA handbook of research methods in psychology, Vol. 2: Research designs: Quantitative, qualitative, neuropsychological, and biological (pp. 333-367). Washington, DC: American Psychological Association.

Husted, B. W. (1999). Wealth, culture, and corruption. Journal of International Business Studies, 30, 339-360.

Inglehart, R., \& Baker, W. E. (2000). Modernization, cultural change, and the persistence of traditional values. American Sociological Review, 65, 19-51. doi: 10.2307/2657288.

International Monetary Fund (2013). Gross Domestic Product 2010-2012. World Economic Outlook Database, April 2013 (accessed September 11, 2016).

Jing, R., \& Graham, J. L. (2008). Values versus regulations: How culture plays its role. Journal of Business Ethics, 80, 791-806. doi: 10.1007/s10551-007-9469-2.

Johnston, M. (2014). Corruption, contention and reform: The power of deep democratization. Cambridge University Press, Cambridge, UK. 
Judge, W. Q., McNatt, D. B., \& Xu, W. (2011). The antecedents and effects of national corruption: A meta-analysis." Journal of World Business, 46, 93-103. doi: 10.1016/j.jwb.2010.05.021

Kant, I. (1993) [1785] Grounding for the metaphysics of morals. Tanslated by J. W. Ellington ( $3^{\text {rd }}$ ed.). Cambridge, MA: Hackett.

Keltner, D., Gruenfeld, D. H., \& Anderson, C. (2003). Power, approach, and inhibition. Psychological Review, 110, 265-284. doi: 10.1037/0033-295X.110.2.265.

Kipnis, D. (1976). The powerholders. University of Chicago Press, Chicago, IL.

Lambsdorff, J. G. (2006). Consequences and causes of corruption - what do we know from a cross-section of countries?" In S. Rose-Ackerman (Ed.), International Handbook on the Economics of Corruption (pp. 3-51). Elgar, Northampton, MA.

Lambsdorff, J. G., \& Schulze, G. G. (2015). What can we know about corruption? A very short history of corruption research and a list of what we should aim for." Jahrbücher für Nationalökonomie und Statistik, 235, 100-114.

Leary, T. (1957). Interpersonal diagnosis of personality. New York, NY: Ronald.

Lee-Chai, A. Y. \& Bargh, J. A. (2001). The use and abuse of power. Multiple perspectives on the causes of corruption. Psychology Press, Philadelphia, PA.

López, J. A. P., \& Santos, J. M. S. (2014). Does corruption have social roots? The role of culture and social capital. Journal of Business Ethics, 122, 697-708. doi: 10.1007/s10551-013-1789-9.

Ly, A. (2013). A critical discussion of Hofstede's concept of Power Distance. SYNAPS, 28, 51-66.

MacCallum, R. C., \& Austin, J. T. (2000). Application of structural equation modeling in psychological research. Annual Review of Psychology, 51, 201-226.

MacKinnon, N. J., \& Heise, D. (2010). Self, identity and social institutions. New York, NY: Palgrave and Macmillan.

March, J. D., \& Simon, H. A. (1958). Organizations. New York: Wiley.

Matsumoto, D., \& Hwang, H. S. (2013). Culture. In K. D. Keith (Ed.), The encyclopedia of cross-cultural psychology (vol. 1). Wiley Blackwell, Chichester, UK.

Mauro, P. (1998). Corruption and the composition of government expenditure. Journal of Public Economics, 69, 263-279. doi: 10.1016/S0047-2727(98)00025-5.

McSweeney, B. (2002). Hofstede's model of national cultural differences and their consequences: A triumph of faith - a failure of analysis". Human Relations, 55, 89-118. doi: $10.1177 / 0018726702551004$.

Mensah, Y. M. (2014). An analysis of the effect of culture and religion on perceived corruption in a global context. Journal of Business Ethics, 121, 255-282. doi: 10.1007/s10551-013-1696-0.

Mitchell, T. R., Hopper, H., Daniels, D., Falvy, J. G., \& Ferris, G. R. (1998). Power, accountability, and inappropriate actions. Applied Psychology, 47, 497-517. doi: 10.1111/j.1464-0597.1998.tb00040.x.

Mulder, M. (1977). The daily power game. Leiden: Stenfert Kroeze.

Pemstein, D., Meserve, S. A., \& Melton, J. (2010). Democratic compromise: A latent variable analysis of ten measures of regime type. Political Analysis, 18, 426-449. doi: 10.1093/pan/mpq020. 
Pieper, A. (2005). Die Ambivalenz der Macht. Ethik-Symposium des Psychiatriezentrums Münsingen, $C H$. http://www.gef.be.ch/site/gef_pzm_es_pzm pieper_philosophie_def. pdf (accessed 11.3.2018). (The ambivalence of power)

Pieper, A. (2017). Einführung in die Ethik (7. aktual. Aufl.). Tübingen: Narr Francke Attempto. (Introduction to ethics, $7^{\text {th }}$ ed.)

Popper, K. R. (1945). The open society and its enemies (2 vol.). London: Routledge.

Rawls, J. (2001). Justice as Fairness. A Restatement. (Ed. E. Kelly). Cambridge, MA: Harvard University Press.

Rose-Ackerman, S., \& Palifka, B. J. (2016). Corruption and government: Causes, consequences, and reform (2nd ed). Cambridge University Press, New York, NY.

Rothstein, B., \& Teorell, J. (2008). What is quality of government: A theory of impartial political institutions. Governance - an International Journal of Policy, Administration and Institutions, 21, 165-190.

Rothstein, B., \& Uslaner, E. M. (2005). All for all: Equality, corruption, and social trust. World Politics, 58, 41-72. doi: 10.1353/wp.2006.0022.

Scholl, W. (1999). Restrictive control and information pathologies in organizations. Journal of Social Issues, 55, 101-118. doi: 10.1111/0022-4537.00107.

Scholl, W. (2013). The socio-emotional basis of human interaction and communication. How we construct our social world. Social Science Information, 52, 3-33. doi: $10.1177 / 0539018412466607$

Scholl, W. (2014). Innovationskultur, Innovationsprozesse und Innovationserfolge [Innovation culture, innovation process, and innovation success] In W. Scholl, F. Schmelzer, S. Kunert, S. Bedenk, J. Hüttner, J. Pullen \& S. Tirre, Mut zu Innovationen Impulse aus Forschung, Beratung und Ausbildung (S. 77-99). Springer Gabler, Wiesbaden, Germany.

Scholl, W., \& Riedel, E. (2010). Using high or low power as promotive or restrictive control differential effects on learning and performance. Social Influence, 5, 40-58. doi: 10.1080/15534510903160522.

Schwartz, S. H. (1992). Universals in the content and structure of values: Theoretical advances and empirical tests in 20 countries. In L. Berkowitz (Ed.), Advances in Experimental Social Psychology (Vol. 25, pp. 1-65). New York: Academic Press.

Singh-Sengupta, S. (1997). The senior managers: Challenges and coping strategies. New Delhi: APH.

Stiglitz, J. (2012). The price of inequality: How today's divided society endangers our future. Norton, New York, NY.

Stiglitz, J., Sen, A., \& Fitoussi, J. P. (2010). Mismeasuring our lives. The New Press, New York, NY.

Thomas, W. I., \& Thomas, D. S. (1928). The child in America: Behavior problems and programs. Knopf, New York, NY.

Transparency International (2016). http://www.transparency.org/glossary/term/corruption. (accessed September 11, 2016).

Treisman, D. (2007). What have we learned about the causes of corruption from ten years of cross-national empirical research? Annual Review of Political Science, 10, 211-244. doi: 10.1146/annurev.polisci.10.081205.095418. (His dataset can be found at http://www.polisci.ucla.edu/faculty/treisman/, last access September 11, 2016). 


\section{Culture and Corruption}

United Nations (1948). The universal declaration of human rights. http://www.un.org/en/universal-declaration-human-rights/index.html (accessed March $11,2018)$.

United Nations (2016). Sustainable Development Goals. At www.un.org/sustainabledevelopment/peace-justice/, (accessed February 5, 2017.)

United Nations Development Program (2014). Human development report 2014. UNDP, New York, NY. http://hdr.undp.org/en/content/human-development-report-2014 (accessed September 11, 2016).

Van de Vliert, E. (2013). Climato-economic habitats support patterns of human needs, stresses, and freedoms. Behavioral and Brain Sciences 36, 465-521. doi:10.1017/S0140525X12002828.

Weber, M. (1972). Wirtschaft und Gesellschaft [Economy and Society], 5th ed. (first publ. 1921). Mohr-Siebeck, Tübingen, Germany.

World Bank (2016). Trade Openness, 2010-2012. http://databank.worldbank.org/data/reports. (accessed September 11, 2016).

World Values Survey wave 4 (2004). http://www.worldvaluessurvey.org/WVSDocumenta tionWV4.jsp (accessed September 11, 2016).

Wortman, C. B., \& Brehm, J. W. (1975). Responses to uncontrollable outcomes: an integration of reactance theory and the learned helplessness model. In L. Berkowitz, (Ed.), Advances in Experimental Social Psychology (vol. 8). New York, N. Y.: Academic Press. 


\section{Culture and Corruption}

\section{Endnotes}

1 Transparency International distinguishes grand, petty and political corruption which all take place in the public sphere. Grand corruption is done by high-level officials diverting large sums of money, petty corruption by mid- and low-level officials exploiting normal citizens, and political corruption again by highlevel officials who change political rules in order to increase their power, status, and wealth.

2 Note that instead of "affiliation" and "power", terms used by Leary (1957), the originator of this circumplex, these dimensions are sometimes termed "friendly-hostile" and "dominant-submissive" as behavioral dimensions or "communion" and "agency", e.g. Abele and Wojciszke (2013). In fact, these two dimensions are universal dimensions resulting from the feeling dimensions of valence and control, being expressed in nonverbal and verbal communication, and showing up in behavior and personality (Scholl, 2013).

3 Some of these authors use other terms for a similar distinction to promotive and restrictive control.

4 English translation cited from Wikipedia's site 'Categorical imperative'.

5 Kipnis (1976) does not use the verbal distinctions "promotive" and "restrictive", but Buschmeier (1995) showed that the more restrictive the tactics and bases of power are, the more they are used against the interests and autonomy of the other(s), whereas the opposite holds for promotive control.

${ }^{6}$ In terms of multi-level analysis, this would be a top-down cross-level effect. Since only the national level data are available from the used culture surveys, this effect cannot be tested with our data.

7 Different from Hoyle (2012), these authors use the term ,path analysis“ only for structural approaches with manifest variables.

8 In the discussion, Husted (1999) avoids causal terminology and speaks of correlates of corruption which does not correct the regression estimates.

9 Collinearity complicates this description because correlated effects of exogenous variables have to be added for the decomposition of correlations. Thus, the lower collinearity is, the more precise the estimation of the model will be.

10 Two later-developed dimensions by Hofstede were omitted in the current study, because less country data were available.

11 We are grateful to Evert Van de Vliert for this personal recommendation.

12 In case of missing values, averages represent the remaining dimensions.

13 The extended data set is publicly available at https://www.researchgate.net/publication/326156903 Power distribution and Corruption

14 The complete path model with the feedback effect of GDP on Corruption is shown in the supplement S1 below; the recalculated model with filled missings is shown as supplement S2 below.

15 If only Power Distance and Individualism (Hofstede) and In-Group collectivism (GLOBE) would be retained in that index, then Press Freedom would be the only additional predictor of Corruption. This points to the important role of an independent press for the fight against corruption; it is also contained in PBF's Freedom Index.

16 This analysis is available from the first author.

17 Regrettably, the authors don't describe fully their Global Economic Freedom Index and the reference is missing.

18 Cited from Pieper, 2017, p. 231, own translation. 
Culture and Corruption

19 Own translation. 


\section{Supplementary Material}

\section{S.1: Nonrecursive model with feedback from GDP to Low Corruption}

In a review about the relationship between Corruption and GDP, Lambsdorff (2006) exhibited the extent of divergence in the causal assumptions and results of cross-sectional analyses of countries. For testing the complete model including hypothesis 3 , we ran a path analysis with causal feedback between corruption and GDP to examine the relative impact of both causal directions. The resulting model is illustrated in Figure S1.

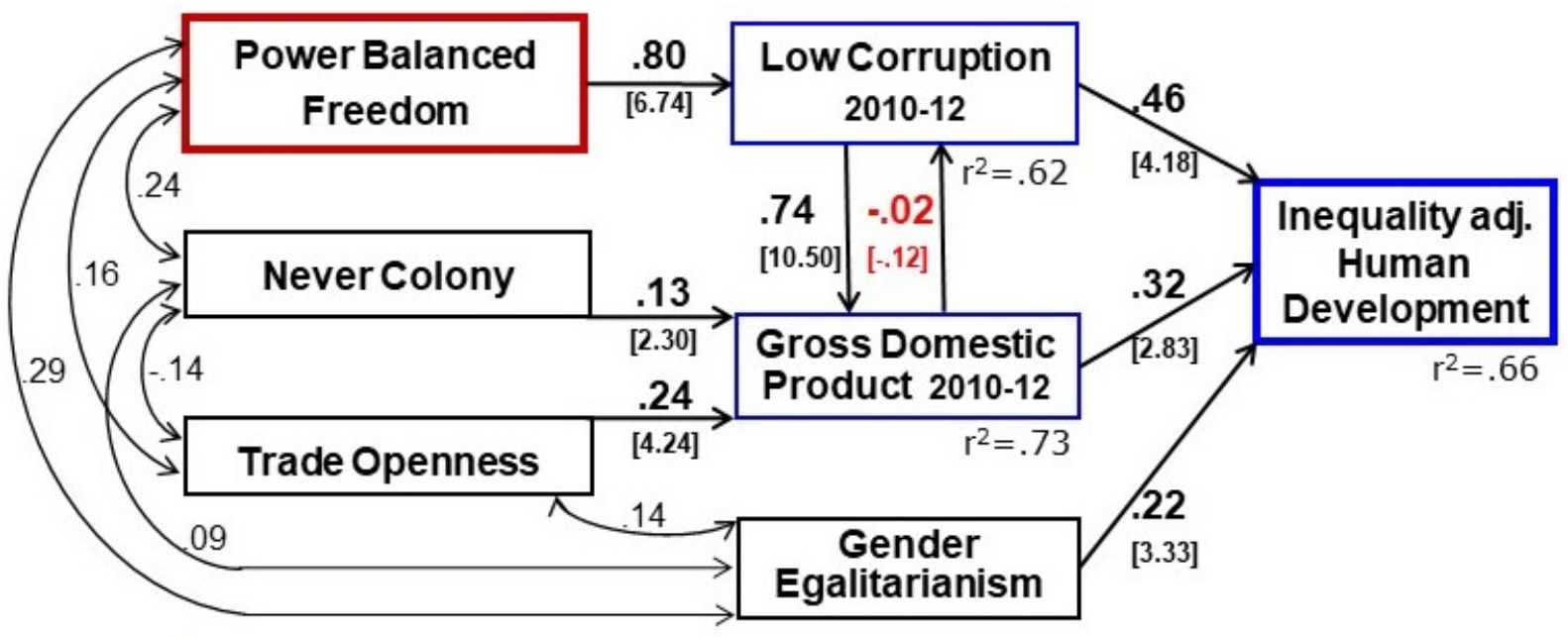

$\mathrm{Chi}^{2}=7.7, \mathrm{df}=7, \mathrm{p}=.36, \mathrm{RMSEA}=.03, \mathrm{SRMR}=.04, \mathrm{CFI}=1.00, \mathrm{NFI}=.98$

Figure S1. Model with feedback effect of low corruption on gross domestic product.

Note. Values on double-headed arrows are correlations between the exogenous variables, numbers on directed arrows are path coefficients (= standardized partial regression coefficients) with t-values in brackets below; $r^{2}$ below the endogenous variables are adjusted explained variances.

Model S1 hardly differs from the accepted model in Figure 4 of the main article, because the recursive effect of GDP on Low Corruption is negligible with -.02. Model S1 has almost the same perfect fitness indices as that in Figure 4. They are only slightly worse compared to $\mathrm{p}=.46$ and RMSEA $=.00$ in the final model of Figure 4 . The paths from the exogenous variables to Corruption and GDP are almost the same. The only remarkable aspect is that the very small and insignificant "explanation" of Low Corruption by GDP does not lower the main effect of PowerBasedFreedom on Low Corruption, as an additional predictor usually does, but strengthens it slightly from .78 to .80 . This compensation effect underlines the interpretation of a one-way causality of Low Corruption to GDP. 


\section{S.2: Reanalysis of the theoretical model from Figure 4 with missing values replaced by culturally related group means}

Missing values are especially a problem with Egalitarianism $(n=56)$, Trade Openness $(\mathrm{n}=76)$ and IHDI $(\mathrm{n}=74)$ instead of $\mathrm{n}=85$ for PBF, CPI, Never Colony, and GDP. To replace these missing values in an adequate way, 15 geographic-cultural groups were formed, supported by historical associations and their bivariate location in figure 3 . Their group averages replaced the missings (see dataset for details). An even better solution is available for IHDI $(n=74)$, which correlates .97 with unadjusted HDI $(n=85)$. Yet, the IHDI values are on average 0.12 points lower than the HDI values because of the inequality adjustments. Thus, for 11 missing IHDI values, the respective available HDI values minus 0.12 were entered into the dataset. Running the LISREL analysis again with the resulting modified correlations gives very similar results, as can be seen by comparing figure S2 with figure 4 .

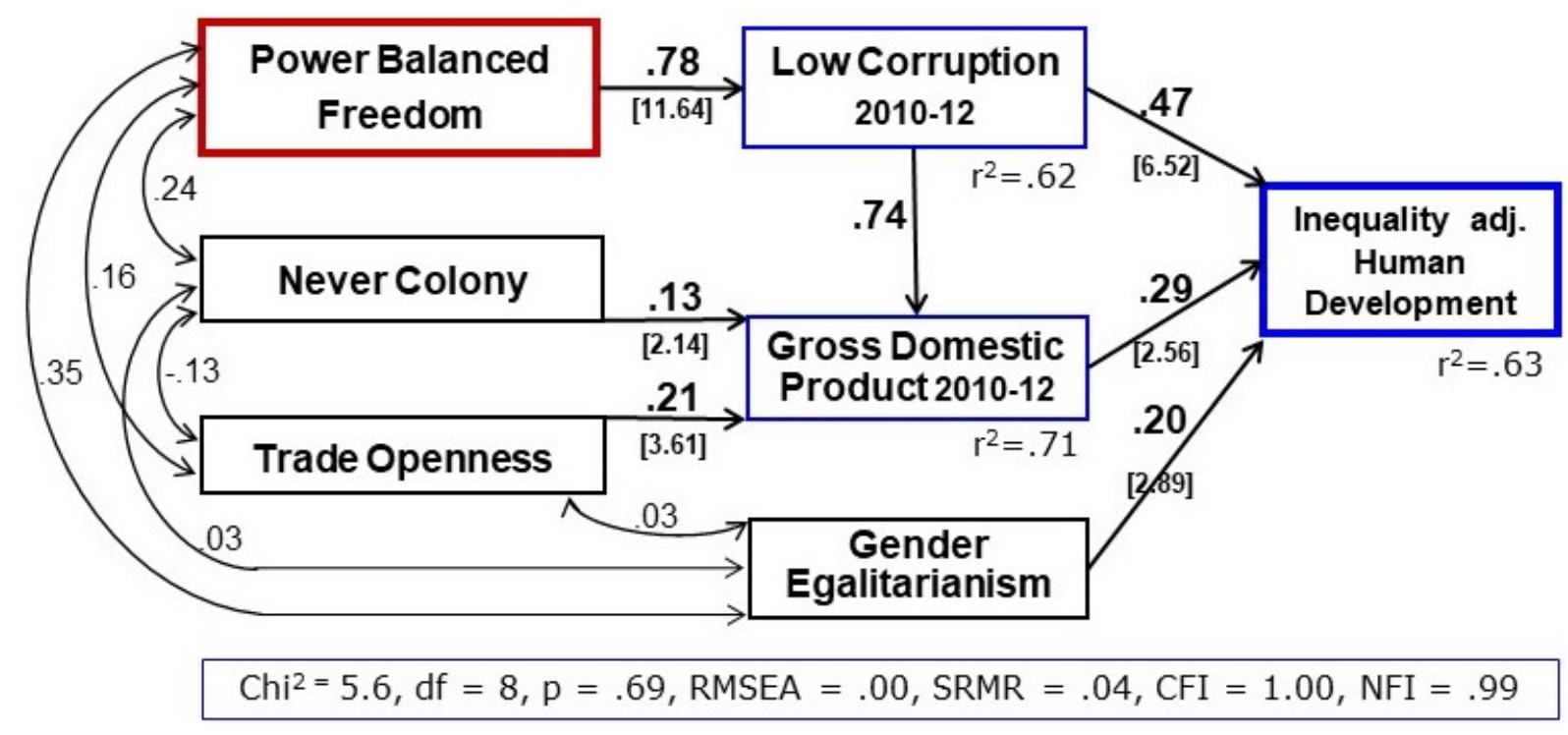

Figure S2. Path model of the cause and the consequences of corruption with missings filled by means of related country-groups (cf. note to figure $\mathrm{S} 1$ )

The adapted model has about the same statistical fitness indices; the higher probability of no deviation from the theoretical model $(\mathrm{p}=.71$ versus .46$)$ and the higher Normed Fitness Index (NFI $=.99$ versus .98$)$ are even slightly better. All path coefficients are significant, the causal structure remains the same, but some paths and the respective explained variances are minimally lower. The latter probably reflects the insertion of group means, which reduced the differentiations between the respective countries. 